\title{
Speed and Oscillations: Medial Septum Integration of Attention and Navigation
}

\section{Marian Tsanov* \\ Trinity College Institute of Neuroscience, Trinity College Dublin, Dublin, Ireland}

Several cortical and diencephalic limbic brain regions incorporate neurons that fire in correlation with the speed of whole-body motion, also known as linear velocity. Besides the field mapping and head-directional information, the linear velocity is among the major signals that guide animal's spatial navigation. Large neuronal populations in the same limbic regions oscillate with theta rhythm during spatial navigation or attention episodes; and the frequency of theta also correlates with linear velocity. A functional similarity between these brain areas is that their inactivation impairs the ability to form new spatial memories; whereas an anatomical similarity is that they all receive projections from medial septum-diagonal band of Broca complex. We review recent findings supporting the model that septal theta rhythm integrates different sensorimotor signals necessary for spatial navigation. The medial septal is described here as a circuitry that mediates experience-dependent balance of sustained attention and path integration during navigation. We discuss the hypothesis that theta rhythm serves as a key mechanism for the aligning of intrinsic spatial representation to: (1) rapid change of position in the spatial environment; (2) continuous alteration of sensory signals throughout navigation; and (3) adapting levels of attentional behavior. The synchronization of these spatial, somatosensory and neuromodulatory signals is proposed here to be anatomically and physiologically mediated by the medial septum.

Frasncisco E. Olucha-Bordonau, Jaume I University, Spain

Reviewed by:

José M. Delgado-García, Universidad Pablo de Olavide, Spain Mehdi Adibi, University of New South Wales, Australia

*Correspondence: Marian Tsanov tsanovm@tcd.ie

Received: 14 June 2017 Accepted: 04 September 2017 Published: 20 September 2017

Citation:

Tsanov M (2017) Speed and Oscillations: Medial Septum Integration of Attention and Navigation.

Front. Syst. Neurosci. 11:67. doi: 10.3389/fnsys.2017.00067

\section{Keywords: medial septum, theta rhythm, linear velocity, path integration, spatial learning}

\section{INTRODUCTION}

Anatomical dissociation of the brain structures mediating: (1) locomotion; (2) rhythmic theta oscillations; and (3) attentional control is not straightforward and easily distinctive. The reason for that is the evolution of these structures, which developed in a similar context-to guide navigation. The dysfunction of these brain areas impairs the motor, spatial or mnemonic components of navigation. The motor, oscillatory and attentional signals converge in several brain regions and one of the most potent convergence is evident in the medial septum. We will describe here each of the main systems that mediate locomotor activity, attentional control and theta rhythmic oscillations, and we will discuss how the convergence of these circuits in the septal region mediates path integration.

\section{LOCOMOTOR CIRCUITS IN THE BRAIN}

Locomotion in mammals is triggered by neural networks of spinal neurons located in the lumbar and cervical segments of the spinal cord. These networks are known as locomotor central pattern generators and they are sufficient to process continuous rhythmic muscle innervation towards 
the limbs, which constitutes the physiology of locomotion (Grillner and Zangger, 1979; Grillner et al., 1981; Kjaerulff and Kiehn, 1996; Marder and Calabrese, 1996; Whelan, 1996; Jordan, 1998). The primary mechanism of locomotor central pattern generation is based on rhythmic feedback loop involving excitatory and inhibitory feedback between the flexor and extensor spinal cord roots (Hinckley et al., 2005; Juvin et al., 2005; McCrea and Rybak, 2008; Frigon and Gossard, 2009). This basic evolutionary principle for whole-body movement of vertebrates demonstrates the fundamental link between locomotion and rhythmic neuronal activity.

Hierarchically-organized brain networks provide descending projections to the central pattern generators for the initiation and the control of the locomotion (Figure 1). Despite the complexity of their connectivity and function the rhythmogenic structures share similar pattern of organization (Butera et al., 1999). On the top of this hierarchical network the medial septum displays a neuronal microarchitecture that leads to rhythmic pattern generation (Wang, 2002). The functional interactions between the supraspinal locomotor regions is complex as none of them serves as self-sufficient pace-maker of the locomotion, however all of them are involved in the regulation of whole-body motion. These brain areas are connected in a system where the signal processing reverberates across all levels of the network and propagates in both ascending and descending anatomical directions (Figure 1).

Electrical stimulation of midbrain nuclei is known to trigger locomotion in decerebrate cats (Shik et al., 1966). Subsequent line of research has led to the concept of mesencephalic locomotor region (MLR), which mediates the supraspinal generation of locomotor activity (Skinner and Garcia-Rill, 1984). The anatomical substrates of MLR are pedunculopontine nucleus, lateral cuneiform nucleus and midbrain extrapyramidal area (Sherman et al., 2015). The function of MLR as locomotor center has been considerably debated (Jordan, 1998) because selective activation of these nuclei in non-decerebrate mammals results in inconsistent locomotor outcome, affecting also the posture, gate, startle response, aversive behavior, cardiovascular and respiratory functions (DiMarco et al., 1983; Mitchell et al., 1988a,b; Mori et al., 1989; Depoortere et al., 1990; Kafkafi et al., 2003; Shafei and Nasimi, 2011; Gariépy et al., 2012; Sherman et al., 2015). The anatomical regions consisting MLR are also implicated in the behavioral state of arousal and rapid eye movement sleep (Brown et al., 2012; Ryczko and Dubuc, 2013; Van Dort et al., 2015; Goetz et al., 2016).

Activation of other brain regions is also linked to the initiation of locomotion. Electrical stimulation of the posterior hypothalamic nucleus induced wheel-running behavior and the running speed increased with increase in stimulation intensity (Bland and Vanderwolf, 1972; Bland et al., 2006). However, stimulation of hierarchically high-positioned brain structures does not lead to single output and the evaluation of the behavioral response after their stimulation is obscured by the functional complexity and diverse connectivity of these structures. The role of the regions comprising the supraspinal locomotor control is elucidated after their inactivation. While electrical stimulation of the medial septum fails to induce wheel-running behavior (Bland et al., 2006), the initiation of locomotion is blocked when the medial septum is pharmacologically inactivated (Oddie et al., 1996). The effect of septal complex on the locomotion is due to the extensive septal innervation of the pontine reticular formation (Swanson and Cowan, 1979; Kalén and Wiklund, 1989) and mesencephalic tegmental area (Satoh and Fibiger, 1986). Pharmacological inactivation or lesion of the mesencephalic reticular system (Shefchyk et al., 1984; Brudzynski et al., 1993; Sinnamon and Benaur, 1997) leads to suppression of locomotion. The experimental inactivation of the nigro-striatal pathways (Baron et al., 2002) widely supports the clinical manifestation of motor dysfunction, best described in the Parkinson's disease (Albin et al., 1989). Damage to the lateral hypothalamus causes profound physical inactivity in rodents (Levitt and Teitelbaum, 1975; Hara et al., 2001). Major pathway from lateral septum to lateral hypothalamus regulates the speed of locomotion (Bender et al., 2015), and lesions of lateral septum lead to hyperactivity (Sheehan et al., 2004). Finally, the inactivation of medullar and pontine reticular formation, including receptor-specific glutamatergic, noradrenergic, dopaminergic and serotonergic antagonism abolishes the initiation and maintenance of whole-body motion (Jordan et al., 2008).

\section{REINFORCEMENT BEHAVIOR}

While electrical stimulation in medial septum has little effect on locomotor activity, the medial septum is widely recognized as a brain site for intracranial self-stimulation in standard operant conditioning situations. Self-stimulation behavior of animals with stimulation electrodes implanted in the medial parts of the septal complex revealed higher self-stimulation rates and lower self-stimulation thresholds compared to animals implanted in the lateral septum (Cazala et al., 1988). Electrical stimulation of septal region generates self-stimulation behavior, which does not interfere with body mobility and/or with the spatial orientation of the self-stimulated rodents (Olds and Milner, 1954). Therefore, septum-mediated behaviors, including locomotion and spatial navigation, are not generated only in the septal area but across wide network of cortical and subcortical structures. The reinforcement behavior during septal self-stimulation is likely to be mediated by the septo-hypothalamic pathway (Sinnamon, 1993). The lateral hypothalamus is a diencephalic brain area classically implicated in feeding and reward (DiLeone et al., 2003; Harris et al., 2005; Stuber and Wise, 2016). The lateral hypothalamus is densely connected to another brain region that is involved in reward-dependent behavior, namely the dopaminergic ventral tegmental area (Shizgal et al., 1980; Bielajew et al., 2000; Nieh et al., 2015). Implantation of stimulation electrodes in the lateral hypothalamus evokes even higher rates of self-stimulation compared to the septal implantations (Cazala et al., 1988). Ascending septal GABAergic fibers indicate hippocampal involvement in the self-stimulation paradigm. Transgenic J20 mice with diminished density of 


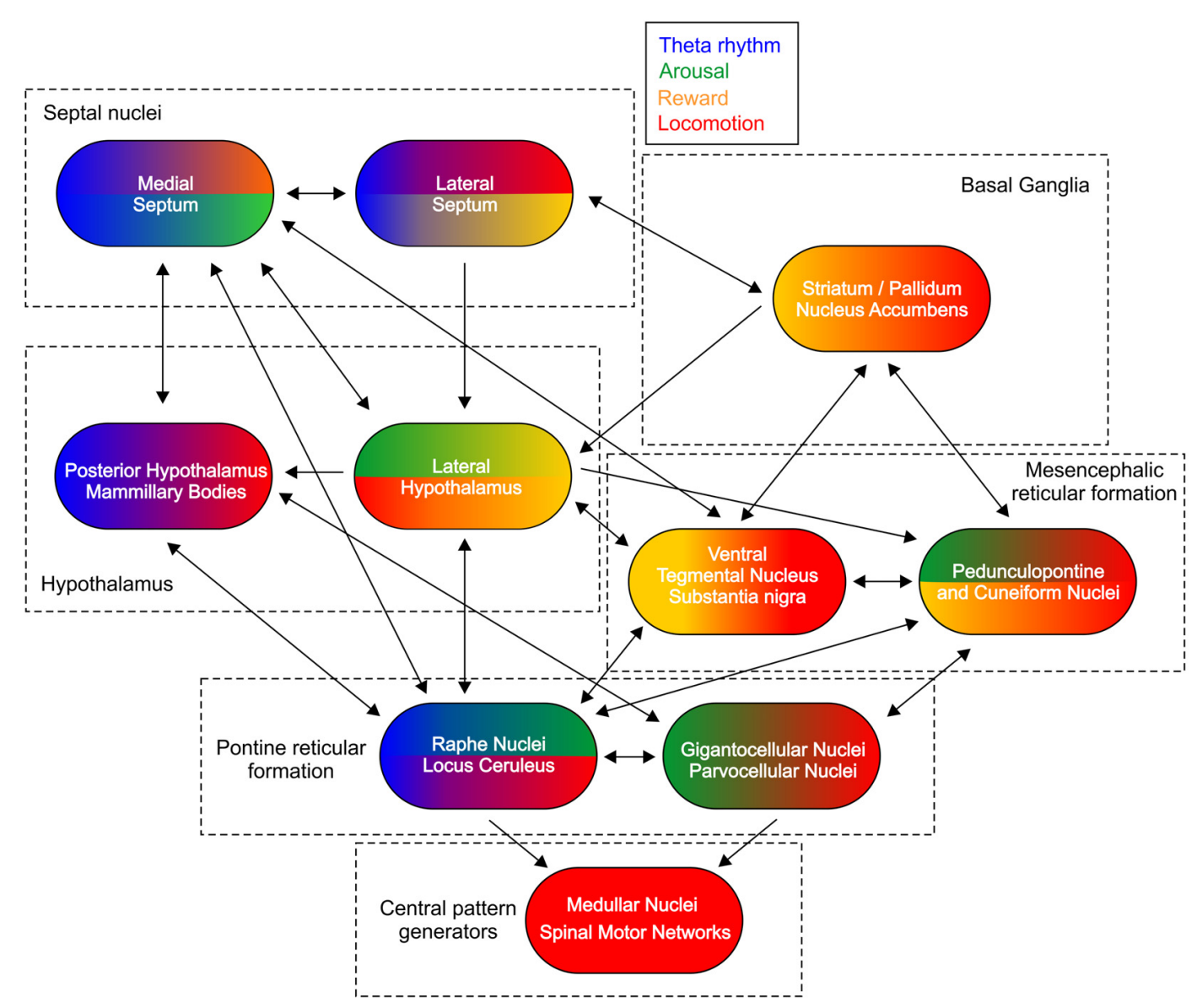

FIGURE 1 | Subcortical control of locomotion. Schematic figure of the main connections between the structures involved in the subcortical control of locomotion. Color-coded representation depicts the functional integration of other major signals for each region. Theta rhythm is marked with blue color, arousal-green, reward-yellow and locomotion-red.

GABAergic terminals on hippocampal interneurons, displayed a delayed acquisition and a lower performance of septal self-stimulation compared to controls (Vega-Flores et al., 2014b). Furthermore, septal self-stimulation supresses the amplitude of Shaffer collaterals-triggered field excitatory postsynaptic potential in wild type mice, but not in J20 mice. The excitatory postsynaptic potentials induced at the CA3-CA1 synapse are proposed to reflect the learning process of brain stimulation reward paradigm (Vega-Flores et al., 2014a). These data show that the functional integrity of septo-hippocampal pathway is involved in the medial septum-evoked self-stimulation behavior. Early studies debated the contribution of the theta rhythm to the intracranial self-stimulation. No differences in rate of septal self-stimulation response have been observed between stimulation protocols that enhanced or attenuated hippocampal theta rhythm (Ball and Gray, 1971). However, later study found that septal self-stimulation phase-locked to theta rhythm resulted in higher number of lever presses (Buño and Velluti, 1977). The septo-hippocampal circuitry might be involved in the context-dependent learning during reinforcement tasks but not in the sensorimotor components of reward-seeking behavior. Another region may exert the attentional control on septal activity for the acquisition of motor activities in instrumental conditioning. While brief electrical stimulation of hippocampus has no effect on the acquisition of an operant conditioning task by observational learning, the same stimulation protocol applied to the medial prefrontal cortex prevents the proper motor sequence of pressing the lever and going to the feeder to collect the reward (a pellet of food) during the operant conditioning task (Jurado-Parras et al., 2012). The medial prefrontal cortex projects to the cholinergic neurons in medial septum (Gaykema et al., 1991) and the prefrontal innervation of septal area may represent an essential anatomical substrate of the attentional behavior. The spiking activity of population of neurons in the medial prefrontal cortex is shown to increase during attentional performance task (Gill et al., 2000). Prefrontal activation of cortical cholinergic inputs is then proposed to compose a top-down attention system, which augments sensorimotor information processing across multiple sensory and limbic areas via activation of cholinergic inputs (Sarter et al., 2001). Cholinergic neuromodulation exhibits a dual role in the 
locomotor and attentional systems in the brain, which we will discuss next.

\section{ATTENTIONAL CONTROL}

Evolutionarily the acetylcholine has been established as the major neuromuscular signal transmitter. In vertebrates the motor neurons are cholinergic and they release acetylcholine at the neuromuscular junction to initiate a muscle contraction. The central nervous system evolved to control the initiation and duration of rhythmically-generated body movements from the spinal motor networks. With the evolution of the midbrain and forebrain the acetylcholine developed neuromodulatory role in sustaining of attention and promoting arousal (Himmelheber et al., 2000; Jones, 2005). The anatomical location of cholinergic centers of the brain is: (1) the basal forebrain including the medial septum/diagonal band of Broca complex and nucleus basalis (Semba and Fibiger, 1988; Semba, 2004); and (2) mesopontine tegmentum including pedunculopontine and laterodorsal tegmental nuclei (Mesulam et al., 1983; Lee et al., 1988). Cholinergic neurons are also distributed in the basal ganglia (Woolf and Butcher, 1981; Bolam et al., 1984) and the medial habenula (Cuello et al., 1978; Aizawa et al., 2012).

The nuclei in the mesopontine tegmentum contain a heterogeneous neuronal population including cholinergic, GABAergic and glutamatergic cells (Lee et al., 1988), which project in ascending and descending directions. The descending projections target the pontomedullary reticular formation and spinal motor networks (Rye et al., 1988; Semba et al., 1990). The ascending pathways target directly the septal complex (Woolf and Butcher, 1986; Hallanger et al., 1987; Hallanger and Wainer, 1988) or indirectly via the posterior and lateral hypothalamic nuclei (Woolf and Butcher, 1986; Oddie et al., 1994; Ford et al., 1995). The basal forebrain cholinergic region forms diverge cholinergic and GABAergic projections across several cortical areas. Medial septum innervates the limbic cortices (Amaral and Kurz, 1985; Wainer et al., 1985), while the nucleus basalis targets sensory, motor and association cortices (Woolf et al., 1983; Casamenti et al., 1986). This extensive efferent divergence of forebrain cholinergic center promotes its functional role to mediate attentional behavior (Sarter and Bruno, 2000).

The neurophysiological substrate of attention is a complex brain process involving several neuromodulators and multiple cortical and subcortical brain areas (Posner and Petersen, 1990). The cognitive structure of attention includes three modules: alertness (arousal networks), orientation (information from sensory input, multisensory integration and episodic memory formation), and executive control (decision making and motor precision) (Posner and Petersen, 1990; Fan et al., 2002). Behaviorally, attention allows the subject to obtain shortor long-term gains, by optimally sustaining the physiological needs of survival, food and reproduction, as well as novelty exploration and social interactions in mammals. This process involves the dopaminergic neuromodulatory systems mediating reward (Shohamy and Adcock, 2010). The septal cholinergic neurons are innervated by the dopaminergic tegmental inputs (Rutz et al., 2007; Watabe-Uchida et al., 2012; Zarrindast et al., 2012). Reciprocally, the cholinergic system regulates dopamine release from ventral tegmentum. The activation of acetylcholine projections from mesopontine tegmentum and basal forebrain influences the responsiveness of dopamine neurons, regulating the release of dopamine in the ventral tegmental area and substantia nigra (Mena-Segovia et al., 2004; Omelchenko and Sesack, 2006; Winn, 2006). This mutual interplay comprises a major subcortical component of the orienting attentional control (Mena-Segovia et al., 2008).

Large number of human clinical studies and animal psychopharmacological experiments on the cholinergic neuromodulation have implicated the acetylcholine as an essential neuromodulator of sustained attention (Sarter et al., 2001). Lesions of the basal forebrain potently downgrade the reaction times of rodents during spatial attention tasks (Robbins et al., 1989; Muir et al., 1994; Bushnell et al., 1998). Lesions of the cholinergic basal forebrain in monkeys disrupt attention during orientation task (Voytko et al., 1994). Reversible suppression of the neuronal activity in the basal forebrain of rats increased the number of errors in sustained attention performance tasks (Holley et al., 1995; Moore et al., 1995). Cortical efflux of acetylcholine is increased throughout the performance of sustained attention task (Himmelheber et al., 2000). Exposure to behaviorally relevant unconditioned or conditioned stimuli triggers attentional behavior and leads to augmentation of cortical acetylcholine levels (Inglis and Fibiger, 1995; Moore et al., 1995; Acquas et al., 1996; Himmelheber et al., 1998). Septal cholinergic neuromodulation mediates shifting states of the brain and attentional modulation particularly of the limbic system (Hasselmo, 2006; Lee and Dan, 2012), and facilitates hippocampus-dependent memory formation (Everitt and Robbins, 1997; Gold, 2004). The role of attention is essential for both encoding and retrieval of episodic memory (Fernandes et al., 2005). The variability of the hippocampal place cells' spiking depends on the attentional behavioral state of the animals (Olypher et al., 2002) and the place fields are more directionally-selective when the rodents search for food presented in a particular goal location, compared to behavioral protocols where the food is dispersed throughout the recording arena (Markus et al., 1995).

The attentional effect of cholinergic neuromodulation is mediated through amplification of stimulus-related processing (McKenna et al., 1988; Tremblay et al., 1990; Murphy and Sillito, 1991) and increase of signal-to-noise ratios in the cortical target areas (Everitt and Robbins, 1997; Sarter and Bruno, 1997). Attention controls the variability of sensory signals and their integration in the limbic cortices through augmented neuronal synchronization during the perception of task-relevant stimuli. The neurophysiological substrate of attention involves increased power of neuronal oscillations and phase synchronization of neuronal activity (Muzzio et al., 2009). Synchronized population oscillatory increases the temporal synaptic interaction of large number of cells 
as the membrane depolarizations fluctuate synchronously for several pre- and postsynaptic neurons (Hasselmo et al., 2002; Axmacher et al., 2006). Such mechanism facilitates the neuronal processing, signal encoding, memory formation and consolidation (Singer, 1993; Salinas and Sejnowski, 2001). The frequencies of neuronal synchronization that mediate attentional signal processing range from slow (less than $1 \mathrm{~Hz}$; Sirota and Buzsáki, 2005) to high gamma (up to $100 \mathrm{~Hz}$ ) oscillations (Singer and Gray, 1995). The most potent rhythms expressed during attentive states of behavior are theta $(5-12 \mathrm{~Hz})$ and low gamma (30-60 Hz) oscillations (Buzsáki, 2010). Next, we will review the role of medial septum for the limbic oscillatory synchronization in the context of spatial navigation.

\section{THETA OSCILLATIONS AND LINEAR SPEED}

For several decades the medial septum is identified as generator of theta rhythm (Petsche et al., 1962; Stumpf et al., 1962). Numerous findings established the central role of septal region as pace-maker of limbic theta oscillations, thoroughly examined in several fundamental reviews (Bland, 1986; Stewart and Fox, 1990; Vinogradova, 1995; Buzsáki, 2002). Despite the extensive research on septal rhythmogenesis it is still unclear whether theta only synchronizes limbic neuronal activity or if the theta cycle also carries particular information necessary for the hippocampal function. One of the correlates established for theta rhythm power is the linear velocity signal (Vanderwolf, 1969; Whishaw and Vanderwolf, 1973; McFarland et al., 1975). Information about the whole-body motion of the animals is one of the major candidates for theta signal processing (McFarland et al., 1975; Oddie and Bland, 1998; Wyble et al., 2004; Sinnamon, 2006; Geisler et al., 2007). The firing frequency of the cells in the medial septum is modulated by speed with $65 \%$ of the rhythmically-bursting septal cells show a significant correlation between the interburst frequency and the animal's running speed (King et al., 1998). Neurons, with firing patterns that highly correlate to the running whole-body speed are detected in other brain regions; movement-related correlates of single-cell activity is observed in posterior hypothalamus, particularly in the medial mammillary nucleus (Sharp and Turner-Williams, 2005). A large portion of neurons in the interpeduncular and habenular nuclei also show a temporally-coarse correlation with running speed (Sharp et al., 2006). These nuclei are anatomically connected to the medial septum (Herkenham and Nauta, 1977; Groenewegen and Wouterlood, 1988) and functionally they are linked to the basal ganglia and the limbic system (Hikosaka et al., 2008).

Recent optogenetic studies shed more light on the integration of speed and theta from the septal region. Photostimulation of septal glutamatergic VGluT2 neurons triggered locomotion, with velocity and duration that were predicted by the spiking frequency and number of activated VGluT2 cells (Fuhrmann et al., 2015). The three main neuronal types in the septal complex are GABAergic (Freund and Antal, 1988), cholinergic
(Amaral and Kurz, 1985) and glutamatergic (Colom et al., 2005). The bursting frequency of the GABAergic neurons is coupled to septo-hippocampal theta waves (Borhegyi et al., 2004; Bassant et al., 2005; Simon et al., 2006; Hangya et al., 2009), while the role of glutamatergic cells is recently linked to locomotion. The pre-motor activity of the septal VGluT2 neurons predicts the speed of the upcoming movement and also indicates the entrainment of hippocampal theta oscillations (Fuhrmann et al., 2015). These data show that the activity of VGLuT2 neurons mediates the switch from inactive behavior to locomotor activity and integrates whole-body motion with theta rhythm. The locomotioncorrelated activity is not restricted to medial septum but also engages the hippocampal neurons. Locomotion-related firing of VGluT2 septo-hippocampal projections supresses the activity of alveus/oriens interneuron-mediated CA3-CA1 feedforward inhibition prior to the movement initiation. Therefore, the increased firing frequency of VGluT2 cells in the septal region augments the excitability of hippocampal pyramidal cells during navigation (Fuhrmann et al., 2015). Recent finding revealed the involvement of lateral septum in the integration of theta rhythm and locomotion. Optogenetic activation of lateral septum projections targeting lateral hypothalamus shows the role of descending septal pathway in theta-rhythmic regulation of locomotion (Bender et al., 2015). Lateral septal dysfunction is associated with hyperactivity (Sheehan et al., 2004) and a major projections from lateral septum target the lateral hypothalamus, which is part of the diencephalic locomotor circuitry (Sinnamon, 1993). Experiments using photostimulation-evoked regulation of hippocampal theta rhythm in combination with axonal chemogenetic or optogenetic inhibition of hippocampo-septal pathway demonstrate that lateral septum controls the variability and speed of running during exploratory behavior (Bender et al., 2015).

Optogenetic methodology allows us also to test the role of septal cholinergic neuromodulation of theta rhythm. Selective light-triggered depolarization of neurons expressing choline acetyltransferase (ChAT) evokes higher degree of spiking in the medial septum as well as in the dorsal hippocampus during inactive behavioral state, characterized with immobility, compared to active state, characterized with locomotor activity (Mamad et al., 2015). Optogenetic stimulation of septal ChAT neurons increases theta amplitude during the inactive states, while the same stimulating protocol during the active state results in significantly lower theta response (Figure 2A). Concurrent findings show that optogenetic stimulation of septal ChAT neurons promotes theta oscillations and suppresses sharp wave ripples and slow oscillations (Vandecasteele et al., 2014). This effect is expressed in experimental setup under anesthesia, whereas the same protocol elicits insignificant changes in any frequency range when the hippocampal oscillations are entrained by high theta power (Vandecasteele et al., 2014). Despite the behavioral dependency of cholinergic modulation on hippocampal oscillations, the optogenetic activation of septal ChAT neurons induces reliable reset of hippocampal theta rhythm and phase-locking 

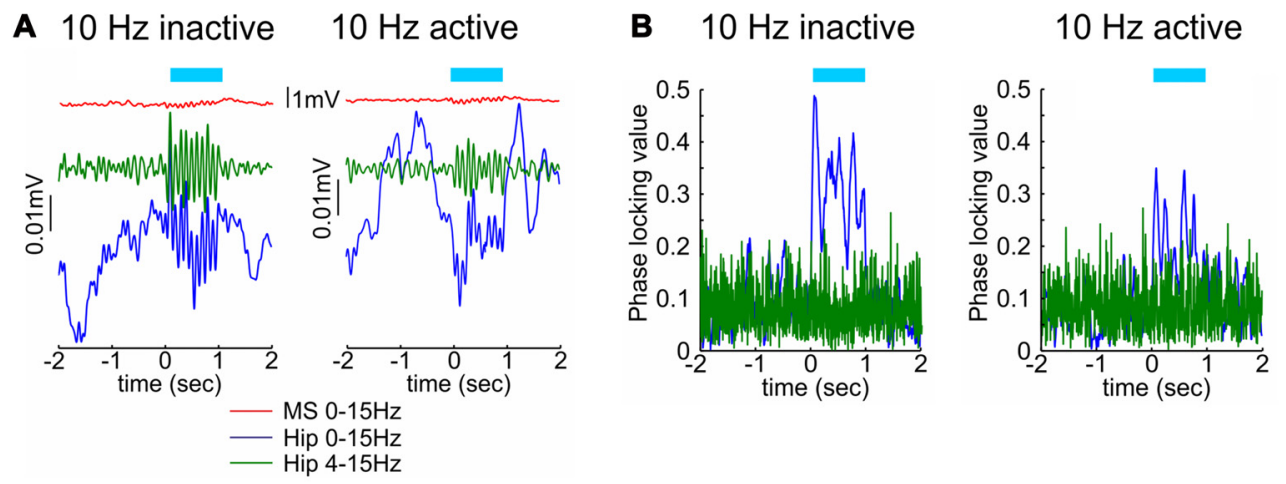

FIGURE 2 | The effect of septal cholinergic activation on hippocampal oscillations depends on the behavioral state. (A) Optogenetic stimulation of cholinergic septal neurons after injection of cre-dependent virus in the medial septum of ChAT::Cre rats. Sample event related potentials (ERP) recorded in hippocampal CA1 region after $10 \mathrm{~Hz}$ septal ChAT photostimulation during inactive (left) and active (right) behavioral state. Upper red traces show ERP from medial septum, middle green traces represent ERP from hippocampus band-pass filtered (4-15 Hz) and lower blue traces represent the same hippocampal ERP after low-pass filtered (0-15 Hz). Time 0 indicates the delivery of the first train of $10 \mathrm{~Hz}$ stimulation protocol to medial septum. (B) Representative samples of phase-locking value for $10 \mathrm{~Hz}$ septal ChAT photostimulation during inactive (left) and active (right) behavioral state. Blue traces show the observed data, while the green values represent shuffled data (adapted from Mamad et al., 2015).

synchronization of CA1 local filed potential (Figure 2B) in behaving rats (Mamad et al., 2015). These data suggest that the septal cholinergic innervation mediates the augmentation of hippocampal network activity during the transition from resting to waking state, but also cholinergic neuromodulation tunes the synchronization of limbic oscillations during active behavior. Earlier study in behaving animals showed that population of slow-spiking septal cells may promote the activation of limbic structures in all behavioral states (Zhang et al., 2011). Concurrently, septal activity precedes temporal power increase of hippocampal theta rhythm that continues for several seconds (Zhang et al., 2011). Inactivation of the septal cholinergic system decreases hippocampal theta power (Lee et al., 1994), however the impact of septal cholinergic activation on hippocampal theta oscillations is restricted to theta power but does not affect theta frequency (Vandecasteele et al., 2014; Mamad et al., 2015). Cholinergic neurons in the medial septum are considered to regulate the amplitude of theta, whereas septal GABAergic cells are believed to mediate the frequency of theta oscillations (Gerashchenko et al., 2001). Current models on theta-rhythm generation across the septo-hippocampal axis describe the interaction between septal and hippocampal GABAergic neurons as a key element in the generation and propagation of theta rhythm (Toth et al., 1997; Chapman and Lacaille, 1999; Buzsáki, 2002). The cholinergic neuromodulation mediates plasticity mechanisms during the theta episodes, supporting the formation of hippocampal memory traces (Huerta and Lisman, 1995; Hyman et al., 2003). Optogenetically-triggered septal cholinergic input, regulates the synaptic plasticity response of CA1 hippocampal neurons to the Schaffer collaterals activation, depending on the timing of cholinergic input relative to the efferent input ( $\mathrm{Gu}$ and Yakel, 2011). These data confirm that septal cholinergic neurons are engaged in limbic neuronal synchronization and mediate synaptic plasticity during exploratory behavior. Overall, these optogenetic findings reveal that cholinergic projections support attentional states, while the glutamatergic projections from medial septum and GABAergic projections from lateral septum regulate locomotor behavior.

\section{SENSORIMOTOR SIGNAL PROCESSING}

When we explore a novel environment (such as touristic trip to a new town) our navigation is guided by spatial cues and we focus our attention to remember them and use them for cue-based trajectory during a subsequent visit. When we are deeply familiar with particular trajectory (such as navigation to our workplace) our attention to the spatial cues is largely diminished and our cognition can focus on other tasks. In the first case our navigation relies of sustained attention, while in the second case our navigation relies on dead reckoning or path integration. Here, we discuss the hypothesis that septal complex is involved in both navigation strategies and septal theta rhythm integrates signals from both modalities (Figure 3A). When animals navigate in environment, the neuronal activity in the limbic formation rhythmically oscillates with a frequency of $5-12 \mathrm{~Hz}$, an oscillatory range known as theta rhythm. Hippocampal theta amplitude and frequency depend on the linear velocity of locomotion and concurrently theta entrains the firing rate of the pyramidal neurons in hippocampus during navigation (Vanderwolf, 1969; Geisler et al., 2007). Hippocampal place cells, which comprise map-based spatial representation (O'Keefe, 1976), linearly enhance their spiking frequency with the locomotor speed (McNaughton et al., 1983; Wiener et al., 1989; Czurkó et al., 1999). The phase of spikes within each theta cycle depends on the spatial location of the animal, the path timing and the instantaneous firing rate of the neuron (O'Keefe and Recce, 1993; Harris et al., 2002; Mehta et al., 2002; 


\section{A Sustained attention}

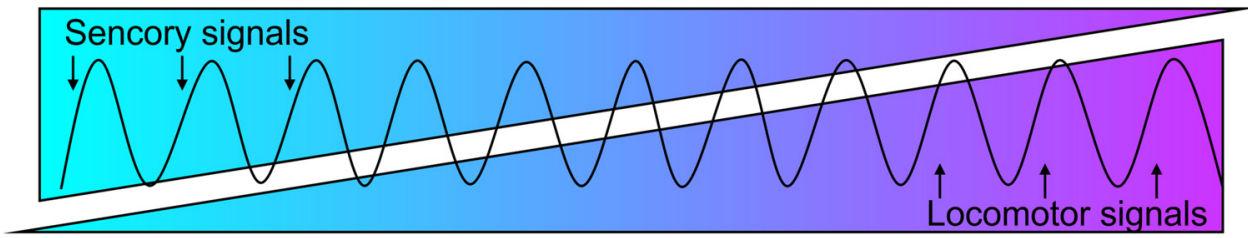

Path integration

\section{experience-dependent spatial navigation familiarity}

\section{B}

\section{Path integration}
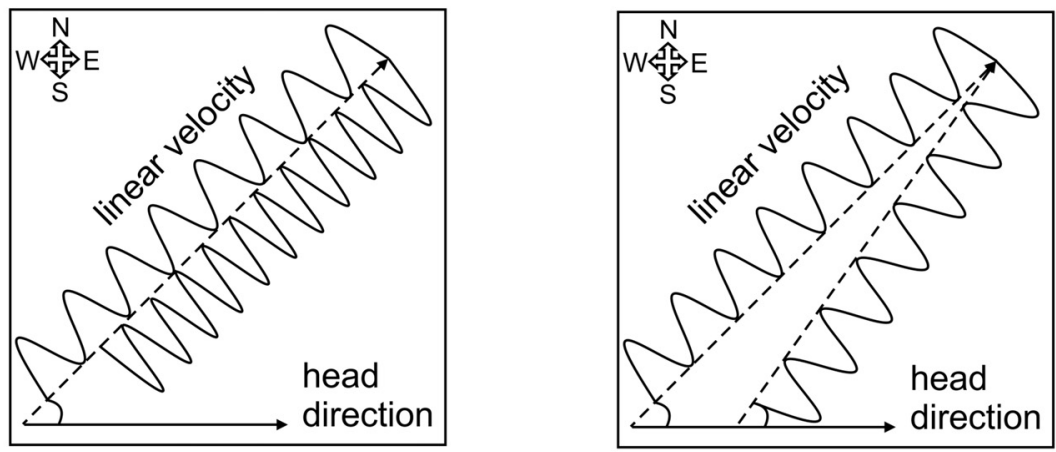

FIGURE 3 | Theta rhythm incorporation of sensorimotor signals and path integration. (A) Schematic presentation of theta rhythm entrainment of sensorimotor signals. The balance between sensory signals (visualized in blue) and locomotor signals (purple) shifts over time after repeated navigation with increased spatial navigation familiarity (depicted with the arrow below). The sensory signals guide sustained attention, while locomotor signal mediate path integration.

(B) Two-dimensional delineation of path integration. Left: spatial navigation towards a goal location with constant angular displacement (measured by the head direction) depends on the velocity value of the linear displacement. Lower linear velocity characterized with slower theta oscillation requires more time to reach the goal location (northeast corner), compared to higher linear velocity characterized with faster oscillation. Right: spatial navigation towards a goal location with constant linear displacement (characterized with the same oscillation frequency) depends on the directional value of the angular displacement from the starting position.

Huxter et al., 2003). The firing rates of the inhibitory neurons in hippocampus are also regulated by locomotion-dependent suppression from the septal GABAergic cells (Fuhrmann et al., 2015).

Navigation is a process, which evolved to integrate sensorimotor signals: while the locomotion provides continuous spatial relocation, the sensory perception provides constant information about each location along the navigation trajectory. During spatial navigation the entorhinal and hippocampal regions integrate multimodal sensory information about the environmental stimuli (Knierim et al., 2013). Besides the visual and auditory signals, sensory information in the course of rodent locomotion is provided via rhythmic movements including sniffing and whisking (Welker et al., 1964). Limbic theta rhythm and whisking/sniffing are independent oscillators (Kepecs et al., 2006), but they synchronize during the sensory perception of task-relevant information (Berg et al., 2006; Buonviso et al., 2006). Therefore, the frequency of somatosensory and olfactory stimuli can be actively synchronized during behaviorally relevant spatial episodes. Medial septum synchronizes respiratory rate and theta oscillations and this integration allows the temporal alignment of intrinsic theta and extrinsic sensorimotor stimuli on each theta cycle. Single-unit recordings in behaving rats show that population of neurons in the medial septum can be phase-locked to the sniffing cycle (Tsanov et al., 2014). The firing of septal fast spiking and theta cells also express a temporal phase bias to the sniff cycle (Tsanov et al., 2014). The sniff cycle is considered as a coherent "timing unit" for olfactory signals processing across the limbic system (Buonviso et al., 2006). Both neuronal spiking and oscillations in olfactory bulb are phase-locked to respiratory cycle (Cang and Isaacson, 2003; Fantana et al., 2008), which can be synchronized with hippocampal theta oscillation (Macrides et al., 1982). Hippocampal theta rhythm and olfactory bulb oscillations correlate during olfactory discrimination tasks (Kay, 2005; Martin C. et al., 2007). These data demonstrate how septumgenerated theta rhythm integrates global limbic oscillations and the activity of single sensory, motor and spatial neurons. Besides the integration of olfactory and somatosensory information, the septal complex controls the limbic incorporation of processed 
visual and auditory signals. Sustained attention performance is attributed to the sparse septal cholinergic innervation of multiple the primary, secondary and associated cortices where the cholinergic projections from the basal forebrain augment the identification and processing of sensory stimuli. Cholinergic neuromodulation increases the excitability of cortical cells to auditory stimuli, facilitating the detection and discrimination of auditory inputs (Weinberger, 1995). In visual cortex the cholinergic innervation enhances the intralaminar transfer of information between cortical columns including enhancement of higher perceptual processes (Xiang et al., 1998; Kimura et al., 1999). Acetylcholine evokes a composite modulation of the excitability of neuronal inputs and outputs to process behaviorally significant stimuli (Hasselmo and Bower, 1992; Tsanov, 2015). Septal cholinergic neuromodulation enhances the spiking of hippocampal pyramidal cells to excitatory afferent inputs (Krnjević et al., 1971; Cole and Nicoll, 1984), and concurrently suppresses the connectivity of glutamatergic synapses (Hounsgaard, 1978; Valentino and Dingledine, 1981; Dutar and Nicoll, 1988; Hasselmo and Bower, 1992). Overall, these findings demonstrate that during spatial navigation, the septal activity integrates sensorimotor signals and enhances the attentional perception of processed sensory information, and its long-term storage (Sarter et al., 2001).

\section{THETA RHYTHM AND PATH INTEGRATION}

When the information about particular trajectory is stored and reliably retrieved after repetitive exposure to the same path, the sustained attention towards spatial cues is gradually decreased (Figure 3A) with prevailing path integration (McNaughton et al., 2006; Taube, 2007). The process by which animals update their estimates of spatial position based on movement signals is known as path integration (Barlow, 1964; Etienne et al., 1996; Whishaw and Wallace, 2003). This process relies on continuous integration of movement information during the navigation (McNaughton et al., 1991; Etienne and Jeffery, 2004). The estimation one's position of at any point can be calculated from (Figure 3B): (1) previously determined position (starting position); (2) linear displacement per time (wholebody speed); and (3) angular displacement (head direction; Whishaw and Gorny, 1999; Wallace et al., 2002; Stackman et al., 2003; Etienne et al., 2004; van der Meer et al., 2010; Valerio and Taube, 2012). Path integration relies on self-motion cues known as idiothetic signals. They include vestibular signals, which detect the head displacement; proprioception signals, which provide information from muscles and joints about limb position; and motor copy efference processed from the motor system during movements' initiation and completion (Etienne et al., 1996; Knierim et al., 1996; McNaughton et al., 2006). The optic flow signals also sustain the continuity of spatial displacement, but this information is more relevant for animals (Collett and Collett, 2000) and humans (Wan et al., 2010), which exquisitely rely on visual cues for navigation. Nocturnal animals, however highly depend on the integration of self-movement cues during navigation. Rodents essentially depend on idiothetic signals to locate a present position (Whishaw and Gorny, 1999; Whishaw et al., 2001; Stackman et al., 2003).

Head-direction cells (Taube et al., 1990) process vestibular signals (Stackman and Taube, 1997; Golob and Taube, 1999; Bassett and Taube, 2001; Sharp et al., 2001b) and their role in the estimation of angular displacement is well-documented (Taube, 1998; Sharp et al., 2001a; Tsanov and O'Mara, 2015). The activity of these neurons, distributed across large network of diencephalic and cortical regions, is a key component of path integration (Muir and Taube, 2002; Taube, 2007). Linear displacement complements the estimation of relocation in the Cartesian plane and serves as major component of the path integration (Etienne and Jeffery, 2004; McNaughton et al., 2006). We know less about the brain systems that process linear velocity and the incorporation of the speed signal in the path integration. One of the major candidates that carry linear velocity signal is septum-generated theta rhythm (Figure 3B). The medial septum is key locus of speed processing due to the following findings: (1) septal neuronal activity correlates to speed (i.e., speed cells; King et al., 1998); (2) inactivation of medial septum abolishes locomotion (Oddie et al., 1996), while septal activation initiates locomotion (Fuhrmann et al., 2015); (3) lesions of medial septum disrupt path integration (Martin M. M. et al., 2007); (4) medial septum is pace-maker of limbic theta oscillations the amplitude and frequency of which depends on locomotor speed (Whishaw and Vanderwolf, 1973; McFarland et al., 1975); and (5) septum-generated theta oscillations depended on linear velocity (Geisler et al., 2007) and the length of traveled distance is directly related to the range of the theta cycle (Gupta et al., 2012). Locomotor speed is closely linked to changes in theta coherence along the limbic system (Hinman et al., 2011), but to become a reference for path integration the speed signal must be incorporated in the mapping of spatial representation. There are two neuronal substrates, which are proposed to integrate spatial signals and velocity-dependent theta oscillations: hippocampal place cells and entorhinal grid cells. Successful path integration depends on hippocampal (Whishaw et al., 1997, 2001) and entorhinal areas (McNaughton et al., 2006; Knierim et al., 2013), where the dysfunction of these limbic structures impairs motion-based navigation. The phase of the neuronal spikes of hippocampal place cells within the theta cycle correlates with the spatial location of the animal and the duration of the path (O'Keefe and Recce, 1993; Harris et al., 2002; Mehta et al., 2002). Theta entrainment of spiking activity of hippocampal interneurons and place cells is controlled by speed (Geisler et al., 2007). The speed-controlled assembly oscillator hypothesis proposes that the assemblies that receive similar information synchronize their activity with a common speed-dependent frequency (Buzsáki, 2010). An elegant research approach demonstrated the hippocampal neurons are capable of encoding time and distance as well as spatial location (Kraus et al., 2013). While rats were running in a treadmill they were trained to hold their position constant. Neurons recorded from dorsal hippocampus were strongly influenced by time and distance. The hippocampal cells encode not only time but also distance, with majority of 
neurons encoding both time and distance (Kraus et al., 2013). "Time cells" in hippocampus can be observed in experimental conditions when during locomotor activity the animal's spatial position is consistently preserved (MacDonald et al., 2011). It is proposed that the medial entorhinal cortex provides spatial information to the hippocampal circuitry, while the lateral entorhinal inputs provide non-spatial input (Deshmukh and Knierim, 2011; Knierim et al., 2013; Van Cauter et al., 2013). Recordings from the medial entorhinal cortex demonstrated that grid cells and non-grid cells also encoded time and distance during animals' running on a treadmill with different running speeds (Kraus et al., 2015). Majority of entorhinal grid cells and other neurons strongly signaled a both distance and time, with populations of cells influenced only by distance or time (Kraus et al., 2015). The neural activity in the entorhinal cortex, thus reflects computation of path distance based on the estimation of both time elapsed and running speed. Medial entorhinal cortex is proposed to mediate path integration computations using intrinsic, self-motion signals and extrinsic sensory information about geometry of the environment (Parron and Save, 2004; Knierim et al., 2013). The key role of the medial entorhinal cortex for the processing of linear velocity signal is revealed by the detection of speed cells (Sargolini et al., 2006; Kropff et al., 2015). Running speed is represented in the spiking frequency of a distinct population of entorhinal neurons different form other cell types such as grid, head-direction and border cells (Kropff et al., 2015). Grid cells, head-direction cells, border cells as well as speed cells within the entorhinal cortex collectively mediate the representation of the spatial position in the environment (Sargolini et al., 2006; Savelli et al., 2008; Solstad et al., 2008). All these neurons are strongly entrained by septum-generated theta oscillations (Giocomo et al., 2007; Brun et al., 2008; Giocomo and Hasselmo, 2008; Hafting et al., 2008). Theoretical models highlight the essential value of septal theta oscillations in spatial navigation where the activity of grid cells is dependent on theta rhythm entrainment and running speed (Hasselmo et al., 2007; Hasselmo, 2013; Shay et al., 2016). Passive transport abolishes velocity modulation of theta rhythmicity and disrupts the grid-like firing pattern of grid cells (Winter et al., 2015). The key role of medial septum for the integration of space and distance is demonstrated in experiments with inactivation of septal region. Pharmacologically-induced suppression of septal activity not only abolishes theta rhythm in the entorhinal-hippocampal network (Rawlins et al., 1979; Mitchell et al., 1982) but also impairs the formation of the grid cells in the entorhinal cortex (Brandon et al., 2011; Koenig et al., 2011). Behaviorally, medial septum inactivation results in impaired spatial learning (Mitchell et al., 1982; Mizumori et al., 1990; Lecourtier et al., 2011) and abolished path integration (Martin M. M. et al., 2007; Jacob et al., 2017). Excitotoxic lesions of medial septum or entorhinal cortex (but not dorsal hippocampus), attenuate the ability of rats to estimate linear distances based on self-movement information (Jacob et al., 2017). Medial septum inactivation impairs animals' capability to run a specific distance in a linear track, using the information generated only by their own displacements (Jacob et al., 2017). Finally, septal lesions lead to deficits in self-motion based navigation and variability of temporal pacing of linear speeds (Martin M. M. et al., 2007).

\section{CONCLUSION}

The contemporary understanding of medial septum is that this region does not simply generate rhythmic oscillations but also integrates variety of processed sensorimotor signals. We know now that sustained attention and spatial navigation crucially depend on the activity of functionally intact medial septum. The widespread cholinergic projections mediate increased neuronal responsiveness for the processing of sensory stimuli during transition from inactive to vigilant behavioral states. Concurrently, the septal inhibitory projections provide functional synchronization across several limbic regions facilitating synaptic transmission and plasticity. There is growing evidence for the significance of septal nuclei in the organization of spatial navigation. One of the main questions that we must address to properly comprehend the role of medial septum is how we can identify different neurophysiological components that combine together to form a distinct behavior. Simple navigation of a rodent in plain environment is complex behavior that involves whole-body motion, sensory perception, spatial orientation, value-dependent evaluation of the environment, awareness of environmental novelty. Despite the efforts of the researchers to separate each of these individual elements of navigation the brain has evolved to process them in parallel and to integrate their signals. Major candidate of this integration is the septal region where the neuronal activity responds to the perception of sensory stimuli, locomotion, arousal and reward. This polyvalent information is entrained in rhythmic theta oscillations, allowing for the theta cycle to serve as a common unit of composite signals. Another dimension that we have to consider when examine navigation is time. Repeated navigation is differently processed by the brain over time. With the increase of familiarity of particular environment the attentional perception of sensory stimuli is gradually replaced by the reliance on locomotor idiothetic signals. This review presented the hypothesis that repeated spatial navigation shifts the information content of theta cycle from sensory to motor signals propagation. We propose here that the septal region provides a dynamic balance between sustained attention and path integration during navigation. In summary, we can firmly outline the medial septum as a brain circuitry that rhythmically integrates processed sensory and motor signals necessary for navigation.

\section{AUTHOR CONTRIBUTIONS}

MT wrote the review.

\section{FUNDING}

This work was supported by Science Foundation Ireland, the Health Research Board and the Wellcome Trust (award no. 099926/Z/12/Z) under Biomedical Research Partnership. 


\section{REFERENCES}

Acquas, E., Wilson, C., and Fibiger, H. C. (1996). Conditioned and unconditioned stimuli increase frontal cortical and hippocampal acetylcholine release: effects of novelty, habituation, and fear. J. Neurosci. 16, 3089-3096.

Aizawa, H., Kobayashi, M., Tanaka, S., Fukai, T., and Okamoto, H. (2012). Molecular characterization of the subnuclei in rat habenula. J. Comp. Neurol. 520, 4051-4066. doi: 10.1002/cne.23167

Albin, R. L., Young, A. B., and Penney, J. B. (1989). The functional anatomy of basal ganglia disorders. Trends Neurosci. 12, 366-375. doi: 10.1016/01662236(89)90074-X

Amaral, D. G., and Kurz, J. (1985). An analysis of the origins of the cholinergic and noncholinergic septal projections to the hippocampal formation of the rat. J. Comp. Neurol. 240, 37-59. doi: 10.1002/cne.902400104

Axmacher, N., Mormann, F., Fernández, G., Elger, C. E., and Fell, J. (2006). Memory formation by neuronal synchronization. Brain Res. Rev. 52, 170-182. doi: 10.1016/j.brainresrev.2006.01.007

Ball, G. G., and Gray, J. A. (1971). Septal self-stimulation and hippocampal activity. Physiol. Behav. 6, 547-549. doi: 10.1016/0031-9384(71)90203-4

Barlow, J. S. (1964). Inertial navigation as a basis for animal navigation. J. Theor. Biol. 6, 76-117. doi: 10.1016/0022-5193(64)90067-0

Baron, M. S., Wichmann, T., Ma, D., and Delong, M. R. (2002). Effects of transient focal inactivation of the basal ganglia in parkinsonian primates. J. Neurosci. 22, 592-599.

Bassant, M. H., Simon, A., Poindessous-Jazat, F., Csaba, Z., Epelbaum, J., and Dournaud, P. (2005). Medial septal GABAergic neurons express the somatostatin sst2A receptor: functional consequences on unit firing and hippocampal theta. J. Neurosci. 25, 2032-2041. doi: 10.1523/jneurosci.4619-04. 2005

Bassett, J. P., and Taube, J. S. (2001). Neural correlates for angular head velocity in the rat dorsal tegmental nucleus. J. Neurosci. 21, 5740-5751.

Bender, F., Gorbati, M., Cadavieco, M. C., Denisova, N., Gao, X., Holman, C., et al. (2015). Theta oscillations regulate the speed of locomotion via a hippocampus to lateral septum pathway. Nat. Commun. 6:8521. doi: 10.1038/ncomms9521

Berg, R. W., Whitmer, D., and Kleinfeld, D. (2006). Exploratory whisking by rat is not phase locked to the hippocampal theta rhythm. J. Neurosci. 26, 6518-6522. doi: 10.1523/jneurosci.0190-06.2006

Bielajew, C., Bushnik, T., Konkle, A. T., and Schindler, D. (2000). The substrate for brain-stimulation reward in the lateral preoptic area. II. Connections to the ventral tegmental area. Brain Res. 881, 112-120. doi: 10.1016/s00068993(00)02565-8

Bland, B. H. (1986). The physiology and pharmacology of hippocampal formation theta rhythms. Prog. Neurobiol. 26, 1-54. doi: 10.1016/0301-0082(86)90019-5

Bland, B. H., Bird, J., Jackson, J., and Natsume, K. (2006). Medial septal modulation of the ascending brainstem hippocampal synchronizing pathways in the freely moving rat. Hippocampus 16, 11-19. doi: 10.1002/hipo.20136

Bland, B. H., and Vanderwolf, C. H. (1972). Diencephalic and hippocampal mechanisms of motor activity in the rat: effects of posterior hypothalamic stimulation on behavior and hippocampal slow wave activity. Brain Res. 43, 67-88. doi: 10.1016/0006-8993(72)90275-2

Bolam, J. P., Wainer, B. H., and Smith, A. D. (1984). Characterization of cholinergic neurons in the rat neostriatum. A combination of choline acetyltransferase immunocytochemistry, Golgi-impregnation and electron microscopy. Neuroscience 12, 711-718. doi: 10.1016/0306-4522(84)90165-9

Borhegyi, Z., Varga, V., Szilágyi, N., Fabo, D., and Freund, T. F. (2004). Phase segregation of medial septal GABAergic neurons during hippocampal theta activity. J. Neurosci. 24, 8470-8479. doi: 10.1523/jneurosci.1413-04.2004

Brandon, M. P., Bogaard, A. R., Libby, C. P., Connerney, M. A., Gupta, K., and Hasselmo, M. E. (2011). Reduction of theta rhythm dissociates grid cell spatial periodicity from directional tuning. Science 332, 595-599. doi: 10.1126/science. 1201652

Brown, R. E., Basheer, R., McKenna, J. T., Strecker, R. E., and McCarley, R. W. (2012). Control of sleep and wakefulness. Physiol. Rev. 92, 1087-1187. doi: 10.1152/physrev.00032.2011

Brudzynski, S. M., Wu, M., and Mogenson, G. J. (1993). Decreases in rat locomotor activity as a result of changes in synaptic transmission to neurons within the mesencephalic locomotor region. Can. J. Physiol. Pharmacol. 71, 394-406. doi: 10.1139/y93-060
Brun, V. H., Solstad, T., Kjelstrup, K. B., Fyhn, M., Witter, M. P., Moser, E. I., et al. (2008). Progressive increase in grid scale from dorsal to ventral medial entorhinal cortex. Hippocampus 18, 1200-1212. doi: 10.1002/hipo.20504

Buño, W. Jr., and Velluti, J. C. (1977). Relationships of hippocampal theta cycles with bar pressing during self-stimulation. Physiol. Behav. 19, 615-621. doi: 10.1016/0031-9384(77)90035-x

Buonviso, N., Amat, C., and Litaudon, P. (2006). Respiratory modulation of olfactory neurons in the rodent brain. Chem. Senses 31, 145-154. doi: 10.1093/chemse/bjj010

Bushnell, P. J., Chiba, A. A., and Oshiro, W. M. (1998). Effects of unilateral removal of basal forebrain cholinergic neurons on cued target detection in rats. Behav. Brain Res. 90, 57-71. doi: 10.1016/S0166-4328(97)00082-X

Butera, R. J. Jr., Rinzel, J., and Smith, J. C. (1999). Models of respiratory rhythm generation in the pre-Bötzinger complex. II. Populations of coupled pacemaker neurons. J. Neurophysiol. 82, 398-415.

Buzsáki, G. (2002). Theta oscillations in the hippocampus. Neuron 33, 325-340. doi: 10.1016/s0896-6273(02)00586-x

Buzsáki, G. (2010). Neural syntax: cell assemblies, synapsembles, and readers. Neuron 68, 362-385. doi: 10.1016/j.neuron.2010.09.023

Cang, J., and Isaacson, J. S. (2003). in vivo whole-cell recording of odor-evoked synaptic transmission in the rat olfactory bulb. J. Neurosci. 23, 4108-4116.

Casamenti, F., Deffenu, G., Abbamondi, A. L., and Pepeu, G. (1986). Changes in cortical acetylcholine output induced by modulation of the nucleus basalis. Brain Res. Bull. 16, 689-695. doi: 10.1016/0361-9230(86)90140-1

Cazala, P., Galey, D., and Durkin, T. (1988). Electrical self-stimulation in the medial and lateral septum as compared to the lateral hypothalamus: differential intervention of reward and learning processes? Physiol. Behav. 44, 53-59. doi: 10.1016/0031-9384(88)90345-9

Chapman, C. A., and Lacaille, J. C. (1999). Cholinergic induction of thetafrequency oscillations in hippocampal inhibitory interneurons and pacing of pyramidal cell firing. J. Neurosci. 19, 8637-8645.

Cole, A. E., and Nicoll, R. A. (1984). Characterization of a slow cholinergic post-synaptic potential recorded in vitro from rat hippocampal pyramidal cells. J. Physiol. 352, 173-188. doi: 10.1113/jphysiol.1984.sp015285

Collett, M., and Collett, T. S. (2000). How do insects use path integration for their navigation? Biol. Cybern. 83, 245-259. doi: 10.1007/s004220000168

Colom, L. V., Castaneda, M. T., Reyna, T., Hernandez, S., and Garrido-Sanabria, E. (2005). Characterization of medial septal glutamatergic neurons and their projection to the hippocampus. Synapse 58, 151-164. doi: 10.1002/syn.20184

Cuello, A. C., Emson, P. C., Paxinos, G., and Jessell, T. (1978). Substance P containing and cholinergic projections from the habenula. Brain Res. 149, 413-429. doi: 10.1016/0006-8993(78)90484-5

Czurkó, A., Hirase, H., Csicsvari, J., and Buzsáki, G. (1999). Sustained activation of hippocampal pyramidal cells by 'space clamping' in a running wheel. Eur. J. Neurosci. 11, 344-352. doi: 10.1046/j.1460-9568.1999.00446.x

Depoortere, R., Sandner, G., and Di Scala, G. (1990). Aversion induced by electrical stimulation of the mesencephalic locomotor region in the intact and freely moving rat. Physiol. Behav. 47, 561-567. doi: 10.1016/0031-9384(90)90127-p

Deshmukh, S. S., and Knierim, J. J. (2011). Representation of non-spatial and spatial information in the lateral entorhinal cortex. Front. Behav. Neurosci. 5:69. doi: 10.3389/fnbeh.2011.00069

DiLeone, R. J., Georgescu, D., and Nestler, E. J. (2003). Lateral hypothalamic neuropeptides in reward and drug addiction. Life Sci. 73, 759-768. doi: 10.1016/s0024-3205(03)00408-9

DiMarco, A. F., Romaniuk, J. R., Von Euler, C., and Yamamoto, Y. (1983). Immediate changes in ventilation and respiratory pattern associated with onset and cessation of locomotion in the cat. J. Physiol. 343, 1-16. doi: 10.1113/jphysiol.1983.sp014878

Dutar, P., and Nicoll, R. A. (1988). Classification of muscarinic responses in hippocampus in terms of receptor subtypes and second-messenger systems: electrophysiological studies in vitro. J. Neurosci. 8, 4214-4224.

Etienne, A. S., and Jeffery, K. J. (2004). Path integration in mammals. Hippocampus 14, 180-192. doi: 10.1002/hipo.10173

Etienne, A. S., Maurer, R., Boulens, V., Levy, A., and Rowe, T. (2004). Resetting the path integrator: a basic condition for route-based navigation. J. Exp. Biol. 207, 1491-1508. doi: 10.1242/jeb.00906

Etienne, A. S., Maurer, R., and Séguinot, V. (1996). Path integration in mammals and its interaction with visual landmarks. J. Exp. Biol. 199, 201-209. 
Everitt, B. J., and Robbins, T. W. (1997). Central cholinergic systems and cognition. Annu. Rev. Psychol. 48, 649-684. doi: 10.1146/annurev.psych. 48.1.649

Fan, J., McCandliss, B. D., Sommer, T., Raz, A., and Posner, M. I. (2002). Testing the efficiency and independence of attentional networks. J. Cogn. Neurosci. 14, 340-347. doi: 10.1162/089892902317361886

Fantana, A. L., Soucy, E. R., and Meister, M. (2008). Rat olfactory bulb mitral cells receive sparse glomerular inputs. Neuron 59, 802-814. doi: 10.1016/j.neuron. 2008.07.039

Fernandes, M. A., Moscovitch, M., Ziegler, M., and Grady, C. (2005). Brain regions associated with successful and unsuccessful retrieval of verbal episodic memory as revealed by divided attention. Neuropsychologia 43, 1115-1127. doi: 10.1016/j.neuropsychologia.2004.11.026

Ford, B., Holmes, C. J., Mainville, L., and Jones, B. E. (1995). GABAergic neurons in the rat pontomesencephalic tegmentum: codistribution with cholinergic and other tegmental neurons projecting to the posterior lateral hypothalamus. J. Comp. Neurol. 363, 177-196. doi: 10.1002/cne.903630203

Freund, T. F., and Antal, M. (1988). GABA-containing neurons in the septum control inhibitory interneurons in the hippocampus. Nature 336, 170-173. doi: 10.1038/336170a0

Frigon, A., and Gossard, J. P. (2009). Asymmetric control of cycle period by the spinal locomotor rhythm generator in the adult cat. J. Physiol. 587, 4617-4628. doi: 10.1113/jphysiol.2009.176669

Fuhrmann, F., Justus, D., Sosulina, L., Kaneko, H., Beutel, T., Friedrichs, D., et al. (2015). Locomotion, theta oscillations, and the speed-correlated firing of hippocampal neurons are controlled by a medial septal glutamatergic circuit. Neuron 86, 1253-1264. doi: 10.1016/j.neuron.2015.05.001

Gariépy, J. F., Missaghi, K., Chevallier, S., Chartré, S., Robert, M., Auclair, F., et al. (2012). Specific neural substrate linking respiration to locomotion. Proc. Natl. Acad. Sci. U S A 109, E84-E92. doi: 10.1073/pnas.1113002109

Gaykema, R. P., van Weeghel, R., Hersh, L. B., and Luiten, P. G. (1991). Prefrontal cortical projections to the cholinergic neurons in the basal forebrain. J. Comp. Neurol. 303, 563-583. doi: 10.1002/cne.903030405

Geisler, C., Robbe, D., Zugaro, M., Sirota, A., and Buzsáki, G. (2007). Hippocampal place cell assemblies are speed-controlled oscillators. Proc. Natl. Acad. Sci. U S A 104, 8149-8154. doi: 10.1073/pnas.0610121104

Gerashchenko, D., Salin-Pascual, R., and Shiromani, P. J. (2001). Effects of hypocretin-saporin injections into the medial septum on sleep and hippocampal theta. Brain Res. 913, 106-115. doi: 10.1016/s00068993(01)02792-5

Gill, T. M., Sarter, M., and Givens, B. (2000). Sustained visual attention performance-associated prefrontal neuronal activity: evidence for cholinergic modulation. J. Neurosci. 20, 4745-4757.

Giocomo, L. M., and Hasselmo, M. E. (2008). Computation by oscillations: implications of experimental data for theoretical models of grid cells. Hippocampus 18, 1186-1199. doi: 10.1002/hipo.20501

Giocomo, L. M., Zilli, E. A., Fransén, E., and Hasselmo, M. E. (2007). Temporal frequency of subthreshold oscillations scales with entorhinal grid cell field spacing. Science 315, 1719-1722. doi: 10.1126/science.1139207

Goetz, L., Piallat, B., Bhattacharjee, M., Mathieu, H., David, O., and Chabardes, S. (2016). The primate pedunculopontine nucleus region: towards a dual role in locomotion and waking state. J. Neural Transm. (Vienna) 123, 667-678. doi: 10.1007/s00702-016-1577-7

Gold, P. E. (2004). Coordination of multiple memory systems. Neurobiol. Learn. Mem. 82, 230-242. doi: 10.1016/j.nlm.2004.07.003

Golob, E. J., and Taube, J. S. (1999). Head direction cells in rats with hippocampal or overlying neocortical lesions: evidence for impaired angular path integration. J. Neurosci. 19, 7198-7211.

Grillner, S., McClellan, A., Sigvardt, K., Wallén, P., and Wilén, M. (1981). Activation of NMDA-receptors elicits "fictive locomotion" in lamprey spinal cord in vitro. Acta Physiol. Scand. 113, 549-551. doi: 10.1111/j.1748-1716.1981. tb06937.x

Grillner, S., and Zangger, P. (1979). On the central generation of locomotion in the low spinal cat. Exp. Brain Res. 34, 241-261. doi: 10.1007/bf00235671

Groenewegen, H. J., and Wouterlood, F. G. (1988). Basal forebrain inputs to the interpeduncular nucleus in the rat studied with the Phaseolus vulgaris-leucoagglutinin tracing method. Brain Res. Bull. 21, 643-649. doi: 10.1016/0361-9230(88)90204-3
Gu, Z., and Yakel, J. L. (2011). Timing-dependent septal cholinergic induction of dynamic hippocampal synaptic plasticity. Neuron 71, 155-165. doi: 10.1016/j. neuron.2011.04.026

Gupta, A. S., van der Meer, M. A., Touretzky, D. S., and Redish, A. D. (2012). Segmentation of spatial experience by hippocampal theta sequences. Nat. Neurosci. 15, 1032-1039. doi: 10.1038/nn.3138

Hafting, T., Fyhn, M., Bonnevie, T., Moser, M. B., and Moser, E. I. (2008). Hippocampus-independent phase precession in entorhinal grid cells. Nature 453, 1248-1252. doi: 10.1038/nature06957

Hallanger, A. E., Levey, A. I., Lee, H. J., Rye, D. B., and Wainer, B. H. (1987). The origins of cholinergic and other subcortical afferents to the thalamus in the rat. J. Comp. Neurol. 262, 105-124. doi: 10.1002/cne.902620109

Hallanger, A. E., and Wainer, B. H. (1988). Ascending projections from the pedunculopontine tegmental nucleus and the adjacent mesopontine tegmentum in the rat. J. Comp. Neurol. 274, 483-515. doi: 10.1002/cne. 902740403

Hangya, B., Borhegyi, Z., Szilágyi, N., Freund, T. F., and Varga, V. (2009). GABAergic neurons of the medial septum lead the hippocampal network during theta activity. J. Neurosci. 29, 8094-8102. doi: 10.1523/jneurosci.566508.2009

Hara, J., Beuckmann, C. T., Nambu, T., Willie, J. T., Chemelli, R. M., Sinton, C. M., et al. (2001). Genetic ablation of orexin neurons in mice results in narcolepsy, hypophagia, and obesity. Neuron 30, 345-354. doi: 10.1016/s08966273(01)00293-8

Harris, K. D., Henze, D. A., Hirase, H., Leinekugel, X., Dragoi, G., Czurko, A., et al. (2002). Spike train dynamics predicts theta-related phase precession in hippocampal pyramidal cells. Nature 417, 738-741. doi: 10.1038/nature00808

Harris, G. C., Wimmer, M., and Aston-Jones, G. (2005). A role for lateral hypothalamic orexin neurons in reward seeking. Nature 437, 556-559. doi: $10.1038 /$ nature 04071

Hasselmo, M. E. (2006). The role of acetylcholine in learning and memory. Curr. Opin. Neurobiol. 16, 710-715. doi: 10.1016/j.conb.2006.09.002

Hasselmo, M. E. (2013). Neuronal rebound spiking, resonance frequency and theta cycle skipping may contribute to grid cell firing in medial entorhinal cortex. Philos. Trans. R Soc. Lond B Biol. Sci. 369:20120523. doi: 10.1098/rstb.2012.0523

Hasselmo, M. E., and Bower, J. M. (1992). Cholinergic suppression specific to intrinsic not afferent fiber synapses in rat piriform (olfactory) cortex. J. Neurophysiol. 67, 1222-1229.

Hasselmo, M. E., Giocomo, L. M., and Zilli, E. A. (2007). Grid cell firing may arise from interference of theta frequency membrane potential oscillations in single neurons. Hippocampus 17, 1252-1271. doi: 10.1002/hipo.20374

Hasselmo, M. E., Hay, J., Ilyn, M., and Gorchetchnikov, A. (2002). Neuromodulation, theta rhythm and rat spatial navigation. Neural Netw. 15, 689-707. doi: 10.1016/s0893-6080(02)00057-6

Herkenham, M., and Nauta, W. J. H. (1977). Afferent connections of the habenular nuclei in the rat. A horseradish peroxidase study, with a note on the fiber-ofpassage problem. J. Comp. Neurol. 173, 123-145. doi: 10.1002/cne.901730107

Hikosaka, O., Sesack, S. R., Lecourtier, L., and Shepard, P. D. (2008). Habenula: crossroad between the basal ganglia and the limbic system. J. Neurosci. 28, 11825-11829. doi: 10.1523/jneurosci.3463-08.2008

Himmelheber, A. M., Fadel, J., Sarter, M., and Bruno, J. P. (1998). Effects of local cholinesterase inhibition on acetylcholine release assessed simultaneously in prefrontal and frontoparietal cortex. Neuroscience 86, 949-957. doi: 10.1016/s0306-4522(98)00097-9

Himmelheber, A. M., Sarter, M., and Bruno, J. P. (2000). Increases in cortical acetylcholine release during sustained attention performance in rats. Brain Res. Cogn. Brain Res. 9, 313-325. doi: 10.1016/s0926-6410(00)00012-4

Hinckley, C. A., Hartley, R., Wu, L., Todd, A., and Ziskind-Conhaim, L. (2005). Locomotor-like rhythms in a genetically distinct cluster of interneurons in the mammalian spinal cord. J. Neurophysiol. 93, 1439-1449. doi: 10.1152/jn.006 47.2004

Hinman, J. R., Penley, S. C., Long, L. L., Escabí, M. A., and Chrobak, J. J. (2011). Septotemporal variation in dynamics of theta: speed and habituation. J. Neurophysiol. 105, 2675-2686. doi: 10.1152/jn.00837.2010

Holley, L. A., Turchi, J., Apple, C., and Sarter, M. (1995). Dissociation between the attentional effects of infusions of a benzodiazepine receptor agonist and an inverse agonist into the basal forebrain. Psychopharmacology (Berl) 120, 99-108. doi: 10.1007/bf02246150 
Hounsgaard, J. (1978). Presynaptic inhibitory action of acetylcholine in area CA1 of the hippocampus. Exp. Neurol. 62, 787-797. doi: 10.1016/00144886(78)90284-4

Huerta, P. T., and Lisman, J. E. (1995). Bidirectional synaptic plasticity induced by a single burst during cholinergic theta oscillation in CA1 in vitro. Neuron 15 , 1053-1063. doi: 10.1016/0896-6273(95)90094-2

Huxter, J., Burgess, N., and O'Keefe, J. (2003). Independent rate and temporal coding in hippocampal pyramidal cells. Nature 425, 828-832. doi: 10.1038/nature02058

Hyman, J. M., Wyble, B. P., Goyal, V., Rossi, C. A., and Hasselmo, M. E. (2003). Stimulation in hippocampal region CA1 in behaving rats yields long-term potentiation when delivered to the peak of theta and long-term depression when delivered to the trough. J. Neurosci. 23, 11725-11731.

Inglis, F. M., and Fibiger, H. C. (1995). Increases in hippocampal and frontal cortical acetylcholine release associated with presentation of sensory stimuli. Neuroscience 66, 81-86. doi: 10.1016/0306-4522(94)00578-s

Jacob, P. Y., Gordillo-Salas, M., Facchini, J., Poucet, B., Save, E., and Sargolini, F. (2017). Medial entorhinal cortex and medial septum contribute to selfmotion-based linear distance estimation. Brain Struct. Funct. 222, 2727-2742. doi: 10.1007/s00429-017-1368-4

Jones, B. E. (2005). From waking to sleeping: neuronal and chemical substrates. Trends Pharmacol. Sci. 26, 578-586. doi: 10.1016/j.tips.2005.09.009

Jordan, L. M. (1998). Initiation of locomotion in mammals. Ann. N Y Acad. Sci. 860, 83-93. doi: 10.1111/j.1749-6632.1998.tb09040.x

Jordan, L. M., Liu, J., Hedlund, P. B., Akay, T., and Pearson, K. G. (2008). Descending command systems for the initiation of locomotion in mammals. Brain Res. Rev. 57, 183-191. doi: 10.1016/j.brainresrev.2007.07.019

Jurado-Parras, M. T., Gruart, A., and Delgado-García, J. M. (2012). Observational learning in mice can be prevented by medial prefrontal cortex stimulation and enhanced by nucleus accumbens stimulation. Learn. Mem. 19, 99-106. doi: $10.1101 / \mathrm{lm} .024760 .111$

Juvin, L., Simmers, J., and Morin, D. (2005). Propriospinal circuitry underlying interlimb coordination in mammalian quadrupedal locomotion. J. Neurosci. 25, 6025-6035. doi: 10.1523/jneurosci.0696-05.2005

Kafkafi, N., Pagis, M., Lipkind, D., Mayo, C. L., Bemjamini, Y., Golani, I., et al. (2003). Darting behavior: a quantitative movement pattern designed for discrimination and replicability in mouse locomotor behavior. Behav. Brain Res. 142, 193-205. doi: 10.1016/s0166-4328(03)00003-2

Kalén, P., and Wiklund, L. (1989). Projections from the medial septum and diagonal band of Broca to the dorsal and central superior raphe nuclei: a non-cholinergic pathway. Exp. Brain Res. 75, 401-416. doi: 10.1007/bf00247947

Kay, L. M. (2005). Theta oscillations and sensorimotor performance. Proc. Natl. Acad. Sci. U S A 102, 3863-3868. doi: 10.1073/pnas.0407920102

Kepecs, A., Uchida, N., and Mainen, Z. F. (2006). The sniff as a unit of olfactory processing. Chem. Senses 31, 167-179. doi: 10.1093/chemse/bjj016

Kimura, F., Fukuda, M., and Tsumoto, T. (1999). Acetylcholine suppresses the spread of excitation in the visual cortex revealed by optical recording: possible differential effect depending on the source of input. Eur. J. Neurosci. 11, 3597-3609. doi: 10.1046/j.1460-9568.1999.00779.x

King, C., Recce, M., and O'Keefe, J. (1998). The rhythmicity of cells of the medial septum/diagonal band of Broca in the awake freely moving rat: relationships with behaviour and hippocampal theta. Eur. J. Neurosci. 10, 464-477. doi: 10.1046/j.1460-9568.1998.00026.x

Kjaerulff, O., and Kiehn, O. (1996). Distribution of networks generating and coordinating locomotor activity in the neonatal rat spinal cord in vitro: a lesion study. J. Neurosci. 16, 5777-5794.

Knierim, J. J., Neunuebel, J. P., and Deshmukh, S. S. (2013). Functional correlates of the lateral and medial entorhinal cortex: objects, path integration and localglobal reference frames. Philos. Trans. R Soc. Lond B Biol. Sci. 369:20130369. doi: 10.1098/rstb.2013.0369

Knierim, J. J., Skaggs, W. E., Kudrimoti, H. S., and McNaughton, B. L. (1996). Vestibular and visual cues in navigation: a tale of two cities. Ann. N Y Acad. Sci. 781, 399-406. doi: 10.1111/j.1749-6632.1996.tb15715.x

Koenig, J., Linder, A. N., Leutgeb, J. K., and Leutgeb, S. (2011). The spatial periodicity of grid cells is not sustained during reduced theta oscillations. Science 332, 592-595. doi: 10.1126/science.1201685

Kraus, B. J., Brandon, M. P., Robinson, R. J. II, Connerney, M. A., Hasselmo, M. E., and Eichenbaum, H. (2015). During running in place, grid cells integrate elapsed time and distance run. Neuron 88, 578-589. doi: 10.1016/j.neuron.2015. 09.031

Kraus, B. J., Robinson, R. J. II, White, J. A., Eichenbaum, H., and Hasselmo, M. E. (2013). Hippocampal "time cells": time versus path integration. Neuron 78, 1090-1101. doi: 10.1016/j.neuron.2013.04.015

Krnjević, K., Pumain, R., and Renaud, L. (1971). The mechanism of excitation by acetylcholine in the cerebral cortex. J. Physiol. 215, 247-268. doi: 10.1113/jphysiol.1971.sp009467

Kropff, E., Carmichael, J. E., Moser, M. B., and Moser, E. I. (2015). Speed cells in the medial entorhinal cortex. Nature 523, 419-424. doi: 10.1038/nature14622

Lecourtier, L., de Vasconcelos, A. P., Leroux, E., Cosquer, B., Geiger, K., Lithfous, S., et al. (2011). Septohippocampal pathways contribute to system consolidation of a spatial memory: sequential implication of GABAergic and cholinergic neurons. Hippocampus 21, 1277-1289. doi: 10.1002/hipo.20837

Lee, M. G., Chrobak, J. J., Sik, A., Wiley, R. G., and Buzsáki, G. (1994). Hippocampal theta activity following selective lesion of the septal cholinergic system. Neuroscience 62, 1033-1047. doi: 10.1016/0306-4522(94) 90341-7

Lee, S. H., and Dan, Y. (2012). Neuromodulation of brain states. Neuron 76, 209-222. doi: 10.1016/j.neuron.2012.09.012

Lee, H. J., Rye, D. B., Hallanger, A. E., Levey, A. I., and Wainer, B. H. (1988). Cholinergic vs. noncholinergic efferents from the mesopontine tegmentum to the extrapyramidal motor system nuclei. J. Comp. Neurol. 275, 469-492. doi: 10.1002/cne.902750402

Levitt, D. R., and Teitelbaum, P. (1975). Somnolence, akinesia, and sensory activation of motivated behavior in the lateral hypothalamic syndrome. Proc. Natl. Acad. Sci. U S A 72, 2819-2823. doi: 10.1073/pnas.72.7.2819

MacDonald, C. J., Lepage, K. Q., Eden, U. T., and Eichenbaum, H. (2011). Hippocampal "time cells" bridge the gap in memory for discontiguous events. Neuron 71, 737-749. doi: 10.1016/j.neuron.2011.07.012

Macrides, F., Eichenbaum, H. B., and Forbes, W. B. (1982). Temporal relationship between sniffing and the limbic theta rhythm during odor discrimination reversal learning. J. Neurosci. 2, 1705-1717.

Mamad, O., McNamara, H. M., Reilly, R. B., and Tsanov, M. (2015). Medial septum regulates the hippocampal spatial representation. Front. Behav. Neurosci. 9:166. doi: 10.3389/fnbeh.2015.00166

Marder, E., and Calabrese, R. L. (1996). Principles of rhythmic motor pattern generation. Physiol. Rev. 76, 687-717.

Markus, E. J., Qin, Y. L., Leonard, B., Skaggs, W. E., McNaughton, B. L., and Barnes, C. A. (1995). Interactions between location and task affect the spatial and directional firing of hippocampal neurons. J. Neurosci. 15, 7079-7094.

Martin, C., Beshel, J., and Kay, L. M. (2007). An olfacto-hippocampal network is dynamically involved in odor-discrimination learning. J. Neurophysiol. 98 , 2196-2205. doi: 10.1152/jn.00524.2007

Martin, M. M., Horn, K. L., Kusman, K. J., and Wallace, D. G. (2007). Medial septum lesions disrupt exploratory trip organization: evidence for septohippocampal involvement in dead reckoning. Physiol. Behav. 90, 412-424. doi: 10.1016/j.physbeh.2006.10.007

McCrea, D. A., and Rybak, I. A. (2008). Organization of mammalian locomotor rhythm and pattern generation. Brain Res. Rev. 57, 134-146. doi: 10.1016/j. brainresrev.2007.08.006

McFarland, W. L., Teitelbaum, H., and Hedges, E. K. (1975). Relationship between hippocampal theta activity and running speed in the rat. J. Comp. Physiol. Psychol. 88, 324-328. doi: 10.1037/h0076177

McKenna, T. M., Ashe, J. H., Hui, G. K., and Weinberger, N. M. (1988). Muscarinic agonists modulate spontaneous and evoked unit discharge in auditory cortex of cat. Synapse 2, 54-68. doi: 10.1002/syn.890020109

McNaughton, B. L., Barnes, C. A., and O’Keefe, J. (1983). The contributions of position, direction, and velocity to single unit activity in the hippocampus of freely-moving rats. Exp. Brain Res. 52, 41-49. doi: 10.1007/bf00 237147

McNaughton, B. L., Battaglia, F. P., Jensen, O., Moser, E. I., and Moser, M. B. (2006). Path integration and the neural basis of the 'cognitive map'. Nat. Rev. Neurosci. 7, 663-678. doi: 10.1038/nrn1932

McNaughton, B. L., Chen, L. L., and Markus, E. J. (1991). "Dead reckoning," landmark learning, and the sense of direction: a neurophysiological and computational hypothesis. J. Cogn. Neurosci. 3, 190-201. doi: 10.1162/jocn. 1991.3.2.190 
Mehta, M. R., Lee, A. K., and Wilson, M. A. (2002). Role of experience and oscillations in transforming a rate code into a temporal code. Nature 417, 741-746. doi: 10.1038/nature00807

Mena-Segovia, J., Bolam, J. P., and Magill, P. J. (2004). Pedunculopontine nucleus and basal ganglia: distant relatives or part of the same family? Br. J. Dermatol. 27, 585-588. doi: 10.1016/j.tins.2004.07.009

Mena-Segovia, J., Winn, P., and Bolam, J. P. (2008). Cholinergic modulation of midbrain dopaminergic systems. Brain Res. Rev. 58, 265-271. doi: 10.1016/j. brainresrev.2008.02.003

Mesulam, M. M., Mufson, E. J., Wainer, B. H., and Levey, A. I. (1983). Central cholinergic pathways in the rat: an overview based on an alternative nomenclature (Ch1-Ch6). Neuroscience 10, 1185-1201. doi: 10.1016/03064522(83)90108-2

Mitchell, I. J., Dean, P., and Redgrave, P. (1988a). The projection from superior colliculus to cuneiform area in the rat. II. Defence-like responses to stimulation with glutamate in cuneiform nucleus and surrounding structures. Exp. Brain Res. 72, 626-639. doi: 10.1007/bf00250607

Mitchell, I. J., Redgrave, P., and Dean, P. (1988b). Plasticity of behavioural response to repeated injection of glutamate in cuneiform area of rat. Brain Res. 460, 394-397. doi: 10.1016/0006-8993(88)90389-7

Mitchell, S. J., Rawlins, J. N., Steward, O., and Olton, D. S. (1982). Medial septal area lesions disrupt theta rhythm and cholinergic staining in medial entorhinal cortex and produce impaired radial arm maze behavior in rats. J. Neurosci. 2, 292-302.

Mizumori, S. J., Perez, G. M., Alvarado, M. C., Barnes, C. A., and McNaughton, B. L. (1990). Reversible inactivation of the medial septum differentially affects two forms of learning in rats. Brain Res. 528, 12-20. doi: 10.1016/0006-8993(90)90188-h

Moore, H., Sarter, M., and Bruno, J. P. (1995). Bidirectional modulation of cortical acetylcholine efflux by infusion of benzodiazepine receptor ligands into the basal forebrain. Neurosci. Lett. 189, 31-34. doi: 10.1016/0304-3940(95) 11444-2

Mori, S., Sakamoto, T., Ohta, Y., Takakusaki, K., and Matsuyama, K. (1989). Sitespecific postural and locomotor changes evoked in awake, freely moving intact cats by stimulating the brainstem. Brain Res. 505, 66-74. doi: 10.1016/00068993(89)90116-9

Muir, J. L., Everitt, B. J., and Robbins, T. W. (1994). AMPA-induced excitotoxic lesions of the basal forebrain: a significant role for the cortical cholinergic system in attentional function. J. Neurosci. 14, 2313-2326.

Muir, G. M., and Taube, J. S. (2002). The neural correlates of navigation: do head direction and place cells guide spatial behavior? Behav. Cogn. Neurosci. Rev. 1, 297-317. doi: 10.1177/1534582302238339

Murphy, P. C., and Sillito, A. M. (1991). Cholinergic enhancement of direction selectivity in the visual cortex of the cat. Neuroscience 40, 13-20. doi: 10.1016/0306-4522(91)90170-s

Muzzio, I. A., Kentros, C., and Kandel, E. (2009). What is remembered? Role of attention on the encoding and retrieval of hippocampal representations. J. Physiol. 587, 2837-2854. doi: 10.1113/jphysiol.2009. 172445

Nieh, E. H., Matthews, G. A., Allsop, S. A., Presbrey, K. N., Leppla, C. A., Wichmann, R., et al. (2015). Decoding neural circuits that control compulsive sucrose seeking. Cell 160, 528-541. doi: 10.1016/j.cell.2015. 01.003

Oddie, S. D., and Bland, B. H. (1998). Hippocampal formation theta activity and movement selection. Neurosci. Biobehav. Rev. 22, 221-231. doi: 10.1016/s01497634(97)00003-1

Oddie, S. D., Bland, B. H., Colom, L. V., and Vertes, R. P. (1994). The midline posterior hypothalamic region comprises a critical part of the ascending brainstem hippocampal synchronizing pathway. Hippocampus 4, 454-473. doi: 10.1002/hipo.450040408

Oddie, S. D., Stefanek, W., Kirk, I. J., and Bland, B. H. (1996). Intraseptal procaine abolishes hypothalamic stimulation-induced wheel-running and hippocampal theta field activity in rats. J. Neurosci. 16, 1948-1956.

O'Keefe, J. (1976). Place units in the hippocampus of the freely moving rat. Exp. Neurol. 51, 78-109. doi: 10.1016/0014-4886(76)90055-8

O'Keefe, J., and Recce, M. L. (1993). Phase relationship between hippocampal place units and the EEG theta rhythm. Hippocampus 3, 317-330. doi: 10.1002/hipo. 450030307
Olds, J., and Milner, P. (1954). Positive reinforcement produced by electrical stimulation of septal area and other regions of rat brain. J. Comp. Physiol. Psychol. 47, 419-427. doi: 10.1037/h0058775

Olypher, A. V., Lánsky, P., and Fenton, A. A. (2002). Properties of the extra-positional signal in hippocampal place cell discharge derived from the overdispersion in location-specific firing. Neuroscience 111, 553-566. doi: 10.1016/s0306-4522(01)00586-3

Omelchenko, N., and Sesack, S. R. (2006). Cholinergic axons in the rat ventral tegmental area synapse preferentially onto mesoaccumbens dopamine neurons. J. Comp. Neurol. 494, 863-875. doi: 10.1002/cne.20852

Parron, C., and Save, E. (2004). Evidence for entorhinal and parietal cortices involvement in path integration in the rat. Exp. Brain Res. 159, 349-359. doi: 10.1007/s00221-004-1960-8

Petsche, H., Stumpf, C., and Gogolak, G. (1962). [The significance of the rabbit's septum as a relay station between the midbrain and the hippocampus. I. The control of hippocampus arousal activity by the septum cells]. Electroencephalogr. Clin. Neurophysiol. 14, 202-211. doi: 10.1016/00134694(62)90030-5

Posner, M. I., and Petersen, S. E. (1990). The attention system of the human brain. Annu. Rev. Neurosci. 13, 25-42. doi: 10.1146/annurev.ne.13.030190.000325

Rawlins, J. N., Feldon, J., and Gray, J. A. (1979). Septo-hippocampal connections and the hippocampal theta rhythm. Exp. Brain Res. 37, 49-63. doi: 10.1007/bf01474253

Robbins, T. W., Everitt, B. J., Marston, H. M., Wilkinson, J., Jones, G. H., and Page, K. J. (1989). Comparative effects of ibotenic acid- and quisqualic acid-induced lesions of the substantia innominata on attentional function in the rat: further implications for the role of the cholinergic neurons of the nucleus basalis in cognitive processes. Behav. Brain Res. 35, 221-240. doi: 10.1016/s0166-4328(89)80143-3

Rutz, S., Riegert, C., Rothmaier, A. K., and Jackisch, R. (2007). Presynaptic modulation of 5-HT release in the rat septal region. Neuroscience 146, 643-658. doi: 10.1016/j.neuroscience.2007.02.005

Ryczko, D., and Dubuc, R. (2013). The multifunctional mesencephalic locomotor region. Curr. Pharm. Des. 19, 4448-4470. doi: 10.2174/1381612811319240011

Rye, D. B., Lee, H. J., Saper, C. B., and Wainer, B. H. (1988). Medullary and spinal efferents of the pedunculopontine tegmental nucleus and adjacent mesopontine tegmentum in the rat. J. Comp. Neurol. 269, 315-341. doi: $10.1002 / \mathrm{cne} .902690302$

Salinas, E., and Sejnowski, T. J. (2001). Correlated neuronal activity and the flow of neural information. Nat. Rev. Neurosci. 2, 539-550. doi: 10.1038/35086012

Sargolini, F., Fyhn, M., Hafting, T., McNaughton, B. L., Witter, M. P., Moser, M. B., et al. (2006). Conjunctive representation of position, direction, and velocity in entorhinal cortex. Science 312, 758-762. doi: 10.1126/science.1125572

Sarter, M., and Bruno, J. P. (1997). Cognitive functions of cortical acetylcholine: toward a unifying hypothesis. Brain Res. Rev. 23, 28-46. doi: 10.1016/s01650173(96)00009-4

Sarter, M., and Bruno, J. P. (2000). Cortical cholinergic inputs mediating arousal, attentional processing and dreaming: differential afferent regulation of the basal forebrain by telencephalic and brainstem afferents. Neuroscience 95 , 933-952. doi: 10.1016/s0306-4522(99)00487-x

Sarter, M., Givens, B., and Bruno, J. P. (2001). The cognitive neuroscience of sustained attention: where top-down meets bottom-up. Brain Res. Rev. 35, 146-160. doi: 10.1016/s0165-0173(01)00044-3

Satoh, K., and Fibiger, H. C. (1986). Cholinergic neurons of the laterodorsal tegmental nucleus: efferent and afferent connections. J. Comp. Neurol. 253, 277-302. doi: 10.1002/cne.902530302

Savelli, F., Yoganarasimha, D., and Knierim, J. J. (2008). Influence of boundary removal on the spatial representations of the medial entorhinal cortex. Hippocampus 18, 1270-1282. doi: 10.1002/hipo.20511

Semba, K. (2004). Phylogenetic and ontogenetic aspects of the basal forebrain cholinergic neurons and their innervation of the cerebral cortex. Prog. Brain Res. 145, 3-43. doi: 10.1016/s0079-6123(03)45001-2

Semba, K., and Fibiger, H. C. (1988). Time of origin of cholinergic neurons in the rat basal forebrain. J. Comp. Neurol. 269, 87-95. doi: 10.1002/cne.902690107

Semba, K., Reiner, P. B., and Fibiger, H. C. (1990). Single cholinergic mesopontine tegmental neurons project to both the pontine reticular formation and the thalamus in the rat. Neuroscience 38, 643-654. doi: 10.1016/03064522(90)90058-c 
Shafei, M. N., and Nasimi, A. (2011). Effect of glutamate stimulation of the cuneiform nucleus on cardiovascular regulation in anesthetized rats: role of the pontine Kolliker-Fuse nucleus. Brain Res. 1385, 135-143. doi: 10.1016/j. brainres.2011.02.046

Sharp, P. E., Blair, H. T., and Cho, J. (2001a). The anatomical and computational basis of the rat head-direction cell signal. Trends Neurosci. 24, 289-294. doi: 10.1016/s0166-2236(00)01797-5

Sharp, P. E., Tinkelman, A., and Cho, J. (2001b). Angular velocity and head direction signals recorded from the dorsal tegmental nucleus of gudden in the rat: implications for path integration in the head direction cell circuit. Behav. Neurosci. 115, 571-588. doi: 10.1037/0735-7044.115.3.571

Sharp, P. E., and Turner-Williams, S. (2005). Movement-related correlates of single-cell activity in the medial mammillary nucleus of the rat during a pelletchasing task. J. Neurophysiol. 94, 1920-1927. doi: 10.1152/jn.00194.2005

Sharp, P. E., Turner-Williams, S., and Tuttle, S. (2006). Movement-related correlates of single cell activity in the interpeduncular nucleus and habenula of the rat during a pellet-chasing task. Behav. Brain Res. 166, 55-70. doi: 10.1016/j. bbr.2005.07.004

Shay, C. F., Ferrante, M., Chapman, G. W. IV, and Hasselmo, M. E. (2016). Rebound spiking in layer II medial entorhinal cortex stellate cells: possible mechanism of grid cell function. Neurobiol. Learn. Mem. 129, 83-98. doi: $10.1016 /$ j.nlm.2015.09.004

Sheehan, T. P., Chambers, R. A., and Russell, D. S. (2004). Regulation of affect by the lateral septum: implications for neuropsychiatry. Brain Res. Rev. 46, 71-117. doi: 10.1016/j.brainresrev.2004.04.009

Shefchyk, S. J., Jell, R. M., and Jordan, L. M. (1984). Reversible cooling of the brainstem reveals areas required for mesencephalic locomotor region evoked treadmill locomotion. Exp. Brain Res. 56, 257-262. doi: 10.1007/bf00 236281

Sherman, D., Fuller, P. M., Marcus, J., Yu, J., Zhang, P., Chamberlin, N. L., et al. (2015). Anatomical location of the mesencephalic locomotor region and its possible role in locomotion, posture, cataplexy, and Parkinsonism. Front. Neurol. 6:140. doi: 10.3389/fneur.2015.00140

Shik, M. L., Severin, F. V., and Orlovskii, G. N. (1966). Control of walking and running by means of electric stimulation of the midbrain. Biofizika 11, 659-666.

Shizgal, P., Bielajew, C., Corbett, D., Skelton, R., and Yeomans, J. (1980). Behavioral methods for inferring anatomical linkage between rewarding brain stimulation sites. J. Comp. Physiol. Psychol. 94, 227-237. doi: 10.1037/h 0077668

Shohamy, D., and Adcock, R. A. (2010). Dopamine and adaptive memory. Trends Cogn. Sci. 14, 464-472. doi: 10.1016/j.tics.2010.08.002

Simon, A. P., Poindessous-Jazat, F., Dutar, P., Epelbaum, J., and Bassant, M. H. (2006). Firing properties of anatomically identified neurons in the medial septum of anesthetized and unanesthetized restrained rats. J. Neurosci. 26, 9038-9046. doi: 10.1523/JNEUROSCI.1401-06.2006

Singer, W. (1993). Synchronization of cortical activity and its putative role in information processing and learning. Annu. Rev. Physiol. 55, 349-374. doi: 10.1146/annurev.ph.55.030193.002025

Singer, W., and Gray, C. M. (1995). Visual feature integration and the temporal correlation hypothesis. Annu. Rev. Neurosci. 18, 555-586. doi: 10.1146/annurev.ne.18.030195.003011

Sinnamon, H. M. (1993). Preoptic and hypothalamic neurons and the initiation of locomotion in the anesthetized rat. Prog. Neurobiol. 41, 323-344. doi: 10.1016/0301-0082(93)90003-b

Sinnamon, H. M. (2006). Decline in hippocampal theta activity during cessation of locomotor approach sequences: amplitude leads frequency and relates to instrumental behavior. Neuroscience 140, 779-790. doi: 10.1016/j.neuroscience. 2006.02.058

Sinnamon, H. M., and Benaur, M. (1997). GABA injected into the anterior dorsal tegmentum (ADT) of the midbrain blocks stepping initiated by stimulation of the hypothalamus. Brain Res. 766, 271-275. doi: 10.1016/s00068993(97)00734-8

Sirota, A., and Buzsáki, G. (2005). Interaction between neocortical and hippocampal networks via slow oscillations. Thalamus Relat. Syst. 3, 245-259. doi: $10.1017 / \mathrm{s} 1472928807000258$

Skinner, R. D., and Garcia-Rill, E. (1984). The mesencephalic locomotor region (MLR) in the rat. Brain Res. 323, 385-389. doi: 10.1016/0006-8993(84)90319-6
Solstad, T., Boccara, C. N., Kropff, E., Moser, M. B., and Moser, E. I. (2008). Representation of geometric borders in the entorhinal cortex. Science 322, 1865-1868. doi: 10.1126/science.1166466

Stackman, R. W., Golob, E. J., Bassett, J. P., and Taube, J. S. (2003). Passive transport disrupts directional path integration by rat head direction cells. J. Neurophysiol. 90, 2862-2874. doi: 10.1152/jn.00346.2003

Stackman, R. W., and Taube, J. S. (1997). Firing properties of head direction cells in the rat anterior thalamic nucleus: dependence on vestibular input. J. Neurosci. $17,4349-4358$.

Stewart, M., and Fox, S. E. (1990). Do septal neurons pace the hippocampal theta rhythm? Trends Neurosci. 13, 163-168. doi: 10.1016/0166-2236(90)90040-h

Stuber, G. D., and Wise, R. A. (2016). Lateral hypothalamic circuits for feeding and reward. Nat. Neurosci. 19, 198-205. doi: 10.1038/nn.4220

Stumpf, C., Petsche, H., and Gogolak, G. (1962). The significance of the rabbit's septum as a relay station between the midbrain and the hippocampus. II. The differential influence of drugs upon both the septal cell firing pattern and the hippocampus theta activity. Electroencephalogr. Clin. Neurophysiol. 14, 212-219. doi: 10.1016/0013-4694(62)90031-7

Swanson, L. W., and Cowan, W. M. (1979). The connections of the septal region in the rat. J. Comp. Neurol. 186, 621-655. doi: 10.1002/cne.901860408

Taube, J. S. (1998). Head direction cells and the neurophysiological basis for a sense of direction. Prog. Neurobiol. 55, 225-256. doi: 10.1016/s03010082(98)00004-5

Taube, J. S. (2007). The head direction signal: origins and sensory-motor integration. Annu. Rev. Neurosci. 30, 181-207. doi: 10.1146/annurev.neuro.29. 051605.112854

Taube, J. S., Muller, R. U., and Ranck, J. B. Jr. (1990). Head-direction cells recorded from the postsubiculum in freely moving rats. I. Description and quantitative analysis. J. Neurosci. 10, 420-435.

Toth, K., Freund, T. F., and Miles, R. (1997). Disinhibition of rat hippocampal pyramidal cells by GABAergic afferents from the septum. J. Physiol. 500, 463-474. doi: 10.1113/jphysiol.1997.sp022033

Tremblay, N., Warren, R. A., and Dykes, R. W. (1990). Electrophysiological studies of acetylcholine and the role of the basal forebrain in the somatosensory cortex of the cat. II. Cortical neurons excited by somatic stimuli. J. Neurophysiol. 64, $1212-1222$.

Tsanov, M. (2015). Septo-hippocampal signal processing: breaking the code. Prog. Brain Res. 219, 103-120. doi: 10.1016/bs.pbr.2015.04.002

Tsanov, M., Chah, E., Reilly, R., and O'Mara, S. M. (2014). Respiratory cycle entrainment of septal neurons mediates the fast coupling of sniffing rate and hippocampal theta rhythm. Eur. J. Neurosci. 39, 957-974. doi: 10.1111/ejn. 12449

Tsanov, M., and O'Mara, S. M. (2015). Decoding signal processing in thalamohippocampal circuitry: implications for theories of memory and spatial processing. Brain Res. 1621, 368-379. doi: 10.1016/j.brainres.2014.12.003

Valentino, R. J., and Dingledine, R. (1981). Presynaptic inhibitory effect of acetylcholine in the hippocampus. J. Neurosci. 1, 784-792.

Valerio, S., and Taube, J. S. (2012). Path integration: how the head direction signal maintains and corrects spatial orientation. Nat. Neurosci. 15, 1445-1453. doi: $10.1038 / \mathrm{nn} .3215$

Van Cauter, T., Camon, J., Alvernhe, A., Elduayen, C., Sargolini, F., and Save, E. (2013). Distinct roles of medial and lateral entorhinal cortex in spatial cognition. Cereb. Cortex 23, 451-459. doi: 10.1093/cercor/bhs033

van der Meer, M. A., Richmond, Z., Braga, R. M., Wood, E. R., and Dudchenko, P. A. (2010). Evidence for the use of an internal sense of direction in homing. Behav. Neurosci. 124, 164-169. doi: 10.1037/a0 018446

Van Dort, C. J., Zachs, D. P., Kenny, J. D., Zheng, S., Goldblum, R. R., Gelwan, N. A., et al. (2015). Optogenetic activation of cholinergic neurons in the PPT or LDT induces REM sleep. Proc. Natl. Acad. Sci. U S A 112, 584-589. doi: $10.1073 /$ pnas. 1423136112

Vandecasteele, M., Varga, V., Berenyi, A., Papp, E., Barthó, P., Venance, L., et al. (2014). Optogenetic activation of septal cholinergic neurons suppresses sharp wave ripples and enhances theta oscillations in the hippocampus. Proc. Natl. Acad. Sci. U S A 111, 13535-13540. doi: 10.1073/pnas.1411233111

Vanderwolf, C. H. (1969). Hippocampal electrical activity and voluntary movement in the rat. Electroencephalogr. Clin. Neurophysiol. 26, 407-418. doi: 10.1016/0013-4694(69)90092-3 
Vega-Flores, G., Gruart, A., and Delgado-Garcia, J. M. (2014a). Involvement of the GABAergic septo-hippocampal pathway in brain stimulation reward. PLoS One 9:e113787. doi: 10.1371/journal.pone.0113787

Vega-Flores, G., Rubio, S. E., Jurado-Parras, M. T., Gómez-Climent, M. A., Hampe, C. S., Manto, M., et al. (2014b). The GABAergic septohippocampal pathway is directly involved in internal processes related to operant reward learning. Cereb. Cortex 24, 2093-2107. doi: 10.1093/cercor/bht060

Vinogradova, O. S. (1995). Expression, control, and probable functional significance of the neuronal theta-rhythm. Prog. Neurobiol. 45, 523-583. doi: 10.1016/0301-0082(94)00051-i

Voytko, M. L., Olton, D. S., Richardson, R. T., Gorman, L. K., Tobin, J. R., and Price, D. L. (1994). Basal forebrain lesions in monkeys disrupt attention but not learning and memory. J. Neurosci. 14, 167-186.

Wainer, B. H., Levey, A. I., Rye, D. B., Mesulam, M. M., and Mufson, E. J. (1985). Cholinergic and non-cholinergic septohippocampal pathways. Neurosci. Lett. 54, 45-52. doi: 10.1016/s0304-3940(85)80116-6

Wallace, D. G., Hines, D. J., Pellis, S. M., and Whishaw, I. Q. (2002). Vestibular information is required for dead reckoning in the rat. J. Neurosci. 22, 10009-10017.

Wan, X., Wang, R. F., and Crowell, J. A. (2010). The effect of active selection in human path integration. J. Vis. 10:25. doi: 10.1167/10.11.25

Wang, X. J. (2002). Pacemaker neurons for the theta rhythm and their synchronization in the septohippocampal reciprocal loop. J. Neurophysiol. 87, 889-900. doi: 10.1152/jn.00135.2001

Watabe-Uchida, M., Zhu, L., Ogawa, S. K., Vamanrao, A., and Uchida, N. (2012). Whole-brain mapping of direct inputs to midbrain dopamine neurons. Neuron 74, 858-873. doi: 10.1016/j.neuron.2012.03.017

Weinberger, N. M. (1995). Dynamic regulation of receptive fields and maps in the adult sensory cortex. Annu. Rev. Neurosci. 18, 129-158. doi: 10.1146/annurev. neuro.18.1.129

Welker, W. I., Johnson, J. I. Jr., and Pubols, B. H. Jr. (1964). Some morphological and physiological characteristics of the somatic sensory system in raccoons. Am. Zool. 4, 75-94. doi: 10.1093/icb/4.1.75

Whelan, P. J. (1996). Control of locomotion in the decerebrate cat. Prog. Neurobiol. 49, 481-515. doi: 10.1016/0301-0082(96)00028-7

Whishaw, I. Q., and Gorny, B. (1999). Path integration absent in scent-tracking fimbria-fornix rats: evidence for hippocampal involvement in "sense of direction" and "sense of distance" using self-movement cues. J. Neurosci. 19, 4662-4673.

Whishaw, I. Q., Hines, D. J., and Wallace, D. G. (2001). Dead reckoning (path integration) requires the hippocampal formation: evidence from spontaneous exploration and spatial learning tasks in light (allothetic) and dark (idiothetic) tests. Behav. Brain Res. 127, 49-69. doi: 10.1016/s0166-4328(01)00359-x

Whishaw, I. Q., McKenna, J. E., and Maaswinkel, H. (1997). Hippocampal lesions and path integration. Curr. Opin. Neurobiol. 7, 228-234. doi: 10.1016/s09594388(97)80011-6

Whishaw, I. Q., and Vanderwolf, C. H. (1973). Hippocampal EEG and behavior: changes in amplitude and frequency of RSA (theta rhythm) associated with spontaneous and learned movement patterns in rats and cats. Behav. Biol. 8, 461-484. doi: 10.1016/s0091-6773(73)80041-0
Whishaw, I. Q., and Wallace, D. G. (2003). On the origins of autobiographical memory. Behav. Brain Res. 138, 113-119. doi: 10.1016/S0166-4328 (02)00236-X

Wiener, S. I., Paul, C. A., and Eichenbaum, H. (1989). Spatial and behavioral correlates of hippocampal neuronal activity. J. Neurosci. 9, 2737-2763.

Winn, P. (2006). How best to consider the structure and function of the pedunculopontine tegmental nucleus: evidence from animal studies. J. Neurol. Sci. 248, 234-250. doi: 10.1016/j.jns.2006.05.036

Winter, S. S., Mehlman, M. L., Clark, B. J., and Taube, J. S. (2015). Passive transport disrupts grid signals in the parahippocampal cortex. Curr. Biol. 25, 2493-2502. doi: 10.1016/j.cub.2015.08.034

Woolf, N. J., and Butcher, L. L. (1981). Cholinergic neurons in the caudate-putamen complex proper are intrinsically organized: a combined Evans blue and acetylcholinesterase analysis. Brain Res. Bull. 7, 487-507. doi: 10.1016/0361-9230(81)90004-6

Woolf, N. J., and Butcher, L. L. (1986). Cholinergic systems in the rat brain: III. Projections from the pontomesencephalic tegmentum to the thalamus, tectum, basal ganglia, and basal forebrain. Brain Res. Bull. 16, 603-637. doi: 10.1016/0361-9230(86)90134-6

Woolf, N. J., Eckenstein, F., and Butcher, L. L. (1983). Cholinergic projections from the basal forebrain to the frontal cortex: a combined fluorescent tracer and immunohistochemical analysis in the rat. Neurosci. Lett. 40, 93-98. doi: 10.1016/0304-3940(83)90285-9

Wyble, B. P., Hyman, J. M., Rossi, C. A., and Hasselmo, M. E. (2004). Analysis of theta power in hippocampal EEG during bar pressing and running behavior in rats during distinct behavioral contexts. Hippocampus 14, 662-674. doi: 10.1002/hipo.20012

Xiang, Z., Huguenard, J. R., and Prince, D. A. (1998). Cholinergic switching within neocortical inhibitory networks. Science 281, 985-988. doi: 10.1126/science. 281.5379.985

Zarrindast, M. R., Ardjmand, A., Ahmadi, S., and Rezayof, A. (2012). Activation of dopamine D1 receptors in the medial septum improves scopolamineinduced amnesia in the dorsal hippocampus. Behav. Brain Res. 229, 68-73. doi: 10.1016/j.bbr.2011.12.033

Zhang, H., Lin, S. C., and Nicolelis, M. A. (2011). A distinctive subpopulation of medial septal slow-firing neurons promote hippocampal activation and theta oscillations. J. Neurophysiol. 106, 2749-2763. doi: 10.1152/jn. 00267.2011

Conflict of Interest Statement: The author declares that the research was conducted in the absence of any commercial or financial relationships that could be construed as a potential conflict of interest.

Copyright (C) 2017 Tsanov. This is an open-access article distributed under the terms of the Creative Commons Attribution License (CC BY). The use, distribution or reproduction in other forums is permitted, provided the original author(s) or licensor are credited and that the original publication in this journal is cited, in accordance with accepted academic practice. No use, distribution or reproduction is permitted which does not comply with these terms. 